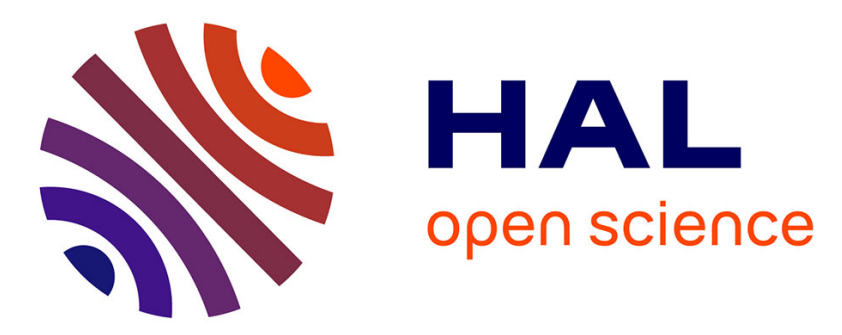

\title{
Disaggregation of MODIS surface temperature over an agricultural area using a time series of Formosat-2 images
}

Olivier Merlin, Benoît Duchemin, Olivier Hagolle, Frédéric Jacob, Benoît Coudert, Ghani Chehbouni, Gérard Dedieu, Jaime Garatuza, Yann H. Kerr

\section{To cite this version:}

Olivier Merlin, Benoît Duchemin, Olivier Hagolle, Frédéric Jacob, Benoît Coudert, et al.. Disaggregation of MODIS surface temperature over an agricultural area using a time series of Formosat-2 images. Remote Sensing of Environment, 2010, 114 (11), pp.2500-2512. 10.1016/j.rse.2010.05.025 . hal-00492470

\section{HAL Id: hal-00492470 \\ https://hal.science/hal-00492470}

Submitted on 23 Jun 2010

HAL is a multi-disciplinary open access archive for the deposit and dissemination of scientific research documents, whether they are published or not. The documents may come from teaching and research institutions in France or abroad, or from public or private research centers.
L'archive ouverte pluridisciplinaire HAL, est destinée au dépôt et à la diffusion de documents scientifiques de niveau recherche, publiés ou non, émanant des établissements d'enseignement et de recherche français ou étrangers, des laboratoires publics ou privés. 


\title{
Disaggregation of MODIS Surface Temperature over an Agricultural Area Using a Time Series of Formosat-2 Images
}

\author{
Olivier Merlin ${ }^{\mathrm{a}}$, Benoit Duchemin ${ }^{\mathrm{a}}$, Olivier Hagolle ${ }^{\mathrm{a}}$, Frédéric Jacob ${ }^{\mathrm{b}}$, \\ Benoit Coudert $^{\mathrm{a}}$, Ghani Chehbouni ${ }^{\mathrm{a}}$, Gérard Dedieu ${ }^{\mathrm{a}}$, Jaime Garatuza ${ }^{\mathrm{c}}$, \\ Yann Kerra \\ ${ }^{a}$ Centre d'Etudes Spatiales de la Biosphère (CESBIO), Toulouse, France \\ ${ }^{b}$ Institut de Recherche pour le Développement, Laboratoire d'étude des Interactions \\ Sol-Agrosystème-Hydrosystème, Montpellier, France \\ ${ }^{c}$ Instituto Tecnológico de Sonora, Sonora, Mexico
}

\section{Abstract}

The temporal frequency of the thermal data provided by current spaceborne high-resolution imagery systems is inadequate for agricultural applications. As an alternative to the lack of high-resolution observations, kilometric thermal data can be disaggregated using a green (photosynthetically active) vegetation index e.g. NDVI (Normalized Difference Vegetation Index) collected at high resolution. Nevertheless, this approach is only valid in the conditions where vegetation temperature is approximately uniform. To extend the validity domain of the classical approach, a new methodology is developed by representing the temperature difference between photosynthetically and non-photosynthetically active vegetation. In practice, both photosynthetically and non-photosynthetically active vegetation fractions are derived from a time series of Formosat-2 shortwave data, and then included in the disaggregation procedure. The approach is tested over a $16 \mathrm{~km}$ by $10 \mathrm{~km}$ irrigated cropping area in Mexico during a whole agricultural season. Kilometric 
MODIS (MODerate resolution Imaging Spectroradiometer) surface temperature is disaggregated at $100 \mathrm{~m}$ resolution, and disaggregated temperature is subsequently compared against concurrent ASTER (Advanced Spaceborne Thermal Emission and Reflection Radiometer) data. Statistical results indicate that the new methodology is more robust than the classical one, and is always more accurate when fractional non-photosynthetically active vegetation cover is larger than 0.10. The mean correlation coefficient and slope between disaggregated and ASTER temperature is increased from 0.75 to 0.81 and from 0.60 to 0.77 , respectively. The approach is also tested using the MODIS data re-sampled at $2 \mathrm{~km}$ resolution. Aggregation reduces errors in MODIS data and consequently increases the disaggregation accuracy. Key words: Disaggregation, scaling, surface temperature, vegetation fraction, albedo, Formosat-2, MODIS, ASTER.

\section{Introduction}

The usefulness of thermal remote sensing data in hydrometeorology and agriculture is intimately related to the temporal frequency and spatial resolution of acquisition. On the one hand, the temporal frequency of $1 \mathrm{~km}$ resolution MODerate resolution Imaging Spectroradiometer (MODIS) and 5 km resolution Geostationary Operational Environmental Satellites (GOES) sensors is larger than 1 image per day. MODIS and GOES are routinely used to monitor drought and surface moisture deficit in relation with climatological forcing at the continental scale (e.g. Nishida et al., 2003; Anderson et al., 2007; Stisen et al., 2008). On the other hand, the temporal frequency of $90 \mathrm{~m}$ resolution Advanced Spaceborne Thermal Emission and Reflection Radiome- 
ter (ASTER) sensor is larger than 15 days. ASTER is used to estimate evapotranspiration over highly heterogeneous landscapes (e.g. Schmugge et al., 1998b; French et al., 2005; Courault et al., 2009), but its relatively long revisit cycle is not convenient for seasonal monitoring (e.g. Norman et al., 1995; Sellers et al., 1995; Norman et al., 2003).

Thanks to the link between surface temperature and hydric status (e.g. Jackson et al., 1981; Boulet et al., 2007; Er-Raki et al., 2008), the potential of thermal data combining high-spatial and high-temporal resolution is considerable in the fields of agriculture and water management. In practice, the spatial and temporal resolution requirements of satellite-derived surface temperature for agricultural applications are estimated as about $40 \mathrm{~m}$ and 1-day revisit (Seguin et al., 1999). To bridge the gap between the lowspatial resolution of available thermal data and the high-spatial resolution required over agricultural areas, one may disaggregate low-spatial-resolution thermal images at high-temporal frequency. To date, most disaggregation approaches of remotely sensed surface temperature have been based on the Normalized Difference Vegetation Index (NDVI) available from shortwave data at a spatial resolution finer than that of thermal data (Kustas et al., 2003; Agam et al., 2007; Inamdar et al., 2008). Although the NDVI-based approach has been successfully tested over agricultural areas, Agam et al. (2007) and Inamdar et al. (2008) emphasized the limitation that the variability of surface temperature is not explained entirely by NDVI. Recently, Inamdar and French (2009) developed a new disaggregation methodology of $5 \mathrm{~km}$ resolution GOES data using $1 \mathrm{~km}$ resolution MODIS-derived surface emissivity. The authors found that the emissivity-based approach was more 
accurate than a similar one based on NDVI. Note that the approach of Inamdar and French (2009) is not applicable to the disaggregation of MODIS type data over agricultural areas. The rationale is that agricultural covers evolve quickly and surface changes drastically between two successive ASTER emissivity products separated by a minimum of 16 days and more often (clouds, programming requests) by several months.

The main limitation of the NDVI-based approach is that the relationship between surface temperature and NDVI is not unique (Agam et al., 2007). It is not unique because (i) NDVI is mostly sensitive to green (photosynthetically active) vegetation cover (e.g. Gutman and Ignatov, 1998) and (ii) surface temperature depends on parameters other than green vegetation cover such as surface soil moisture and non-photosynthetically active vegetation cover (e.g. Moran et al., 1994). Especially, the NDVI over bare soil and over senescent vegetation is expected to be very low in both cases, whereas the radiometric temperature over bare soil may be significantly larger than that over full-cover senescent vegetation. The temperature difference between bare soil and senescent vegetation can be explained by the decrease of aerodynamic resistance with vegetation height facilitating heat release from the surface (e.g. Shuttleworth and Wallace, 1985), and/or by the decrease of net radiation induced by an increase of surface albedo (e.g. Menenti et al., 1989).

In fact, robust disaggregation algorithms of surface temperature should account for all the main parameters involved in the surface energy budget. The difficulty is then to (i) observe these parameters at high-spatial and -temporal resolution and (ii) develop a general framework in which these pa- 
rameters can be consistently integrated into the disaggregation procedure. Accounting for the variability of surface soil moisture is made difficult by the relatively low-spatial resolution (several tens of kilometers) of available observations. In particular, the spatial resolution of the SMOS (Soil Moisture and Ocean Salinity, Kerr et al. (2001)) satellite launched in November 2009 is about $40 \mathrm{~km}$, and that of the forthcoming SMAP (Soil Moisture Active Passive, http://smap.jpl.nasa.gov) mission will be about $10 \mathrm{~km}$. Consequently, the impact of surface soil moisture on surface temperature will not be addressed in this paper. On the other hand, senescent vegetation cover can be estimated at high resolution but no disaggregation procedure has included this parameter yet.

The NDVI-based disaggregation, despite its intrinsic limitations, is among the best of existing methods. The objective of this study is to complement the classical approach of Agam et al. (2007) in the conditions where the temperature difference between photosynthetically and non-photosynthetically active vegetation is significant. The methodology takes advantage of the unique capabilities of the Formosat-2 instrument (Chern et al., 2008) providing shortwave data at high-spatial resolution $(8 \mathrm{~m})$ and high-temporal frequency (potentially 1 image per day). The time series of Formosat-2 reflectances allow a fine analysis of the seasonality of canopies during the crop cycle (Duchemin et al., 2008; Hadria et al., 2010). Specifically, Formosat-2 data can be used to retrieve both fractional photosynthetically and nonphotosynthetically active vegetation covers.

The approach is tested over a $16 \mathrm{~km}$ by $10 \mathrm{~km}$ area near Yaqui in northwestern Mexico. The Yaqui area is adequate to test disaggregation method- 
ologies because surface temperature is highly variable in space due to irrigation practices, crop rotations and a high evaporative demand. Kilometric MODIS Terra surface temperature is disaggregated at $100 \mathrm{~m}$ resolution on seven dates in 2007-2008, and disaggregated temperature is subsequently compared against concurrent ASTER data. Prior to the application to MODIS data, the use of aggregated ASTER data allows evaluating disaggregation approaches independently from differences between ASTER and MODIS products. The methodology is presented (Section 2) and is applied to the ASTER data aggregated at kilometric resolution (Section 3) and to real MODIS data (Section 4). A sensitivity analysis is conducted in Section 5.

\section{Material and Method}

The methodology aims to disaggregate kilometric surface temperature at hectometric $(100 \mathrm{~m})$ resolution following the scheme presented in Figure 1. The $100 \mathrm{~m}$ resolution is chosen to evaluate the results using ASTER, which is currently the spaceborne thermal sensor with the highest spatial resolution.

\subsection{Disaggregation methodology}

The three disaggregation algorithms D0, D1 and D2 are detailed below. D0 does not use any ancillary data. D1 is based on the fractional photosynthetically active vegetation cover estimated at high resolution and is the same as the NDVI-based approach of Agam et al. (2007). Fractional photosynthetically active vegetation cover is noted $f_{\text {pav }}$ and is defined as the surface of green (photosynthetically active) vegetation per soil surface unit. D2 is based on both fractional photosynthetically and non-photosynthetically 
active vegetation covers. In this paper, fractional non-photosynthetically active vegetation cover is expressed as the difference $\left(f_{\mathrm{tv}}-f_{\mathrm{pav}}\right)$ with $f_{\mathrm{tv}}$ being the fraction of total (photosynthetically and non-photosynthetically active) vegetation. All these variables are derived from Formosat-2 images.

D0 simply sets disaggregated temperature $T^{(0)}$ to low-resolution temperature:

$$
T^{(0)}=T_{\mathrm{km}}
$$

with $T_{\mathrm{km}}$ being the temperature available at kilometric resolution. Note that all the variables defined at kilometric scale are written with the subscript $\mathrm{km}$.

D1 sets disaggregated temperature $T^{(1)}$ as:

$$
T^{(1)}=T_{\mathrm{km}}+\mathbf{a}_{\mathbf{1}} \times\left(f_{\mathrm{pav}}-\left\langle f_{\mathrm{pav}}\right\rangle_{\mathrm{km}}\right)
$$

with $\left\langle f_{\text {pav }}\right\rangle_{\mathrm{km}}$ being the average of $f_{\text {pav }}$ within each low-resolution pixel, and $\mathbf{a}_{1}$ the slope of the linear regression between $T_{\mathrm{km}}$ and $\left\langle f_{\text {nav }}\right\rangle_{\mathrm{km}}$. The slope $\mathbf{a}_{1}$ is evaluated at the scale of the satellite image (Agam et al., 2007). Note that all the variables defined at the image scale are written in bold.

D2 accounts for both photosynthetically and non-photosynthetically active vegetation covers. Disaggregated temperature $T^{(2)}$ is written as:

$$
T^{(2)}=T_{\mathrm{km}}+\mathbf{a}_{\mathbf{1}}^{\text {proj }} \times\left(f_{\text {pav }}^{\text {proj }}-\left\langle f_{\text {pav }}^{\text {proj }}\right\rangle_{\mathrm{km}}\right)
$$

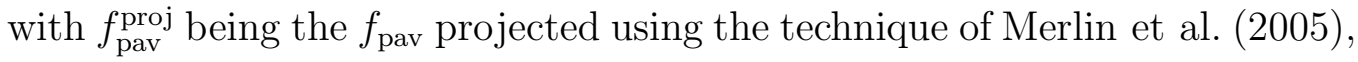
$\left\langle f_{\text {pav }}^{\text {proj }}\right\rangle_{\mathrm{km}}$ its average within kilometric pixels, and $\mathbf{a}_{\mathbf{1}}^{\text {proj }}$ the slope of the linear regression between $T_{\mathrm{km}}$ and $f_{\mathrm{pav}, \mathrm{km}}^{\mathrm{proj}}$, with $f_{\mathrm{pav}, \mathrm{km}}^{\text {proj }}$ being the $f_{\mathrm{pav}}^{\text {proj }}$ estimated at kilometric resolution. 
The projection technique was theoretically developed in Merlin et al. (2005). It was successively applied to $-2.5 \mathrm{~cm}$ soil temperature (Merlin et al., 2006), to surface evaporative fraction (Merlin et al., 2008) and to soil evaporative efficiency (Merlin et al., 2010). It is a robust tool to strengthen the correlation between two variables by representing the dependence of these variables on other additional variables. In this paper, the projection technique is applied to fractional photosynthetically active vegetation cover. It aims at artificially improving the spatial correlation between $T$ and $f_{\text {pav }}$ by accounting for the dependence of $T$ on $f_{\mathrm{tv}}$. Note that $f_{\text {pav }}^{\text {proj }}$ is not a physical variable. It is formally written as:

$$
f_{\text {pav }}^{\text {proj }}=f_{\text {pav }}-\Delta f_{\text {pav }, \text { mod }}
$$

with $\Delta f_{\text {pav, mod }}$ being a corrective term that accounts for the dependence of $T$ on $f_{\mathrm{tv}}$. To derive $\Delta f_{\mathrm{pav}, \text { mod }}$ in Equation (4), $T$ is expressed as:

$$
T=\left(1-f_{\mathrm{tv}}\right) T_{\mathrm{s}}+f_{\mathrm{pav}} \mathbf{T}_{\mathbf{v}, \min }+\left(f_{\mathrm{tv}}-f_{\mathrm{pav}}\right) \mathbf{T}_{\mathbf{v}, \max }
$$

with $T_{\mathrm{s}}$ being the high-resolution soil skin temperature, $\mathbf{T}_{\mathbf{v}}$, min the minimum vegetation temperature observed at low resolution within the study area, and $\mathbf{T}_{\mathbf{v}}$, max the maximum vegetation temperature observed at low resolution within the study area. In Equation (5), surface temperature is linearly decomposed into its soil and vegetation components as a good approximation of the relationship with power $4^{\text {th }}$ for temperatures (Anderson et al., 1997; Merlin and Chehbouni, 2004). Vegetation temperature is also linearly decomposed into the temperature of photosynthetically active vegetation $\mathbf{T}_{\mathbf{v}}$, min and that of non-photosynthetically active vegetation $\mathbf{T}_{\mathbf{v}}$, max. Fol- 
lowing Equation (5), $f_{\text {pav }}$ is modelled by:

$$
f_{\mathrm{pav}, \bmod }=\frac{\left(1-f_{\mathrm{tv}}\right) T_{\mathrm{s}}+f_{\mathrm{tv}} \mathbf{T}_{\mathbf{v}, \max }-T}{\mathbf{T}_{\mathbf{v}, \max }-\mathbf{T}_{\mathbf{v}, \min }}
$$

As $T_{\mathrm{s}}$ is unknown at high resolution, it is set to $\mathbf{T}_{\mathbf{s}}=\left(\mathbf{T}_{\mathbf{s}, \min }+\mathbf{T}_{\mathbf{s}, \max }\right) / 2$ in Equation (6) with $\mathbf{T}_{\mathbf{s}}$, min and $\mathbf{T}_{\mathbf{s}}$, max being the minimum and maximum soil temperature observed at low resolution within the study area, respectively. Setting $T_{\mathrm{s}}$ to a uniform value is a strong assumption. However, one should acknowledge that the main factor of variability of soil temperature is surface soil moisture, which is not available at high resolution. It is reminded that the scope of this study is to focus on the variability of vegetation temperature, and its impact on surface temperature. Surface temperature in Equation (6) is also unknown at high resolution. As a first guess, it is set to its value at low resolution $T_{\mathrm{km}}$. Hence, modelled $f_{\mathrm{pav}}$ becomes:

$$
f_{\mathrm{pav}, \bmod }\left(f_{\mathrm{tv}}\right)=\frac{\left(1-f_{\mathrm{tv}}\right) \mathbf{T}_{\mathbf{s}}+f_{\mathrm{tv}} \mathbf{T}_{\mathbf{v}, \max }-T_{\mathrm{km}}}{\mathbf{T}_{\mathbf{v}, \max }-\mathbf{T}_{\mathbf{v}, \min }}
$$

Finally, the corrective term $\Delta f_{\text {pav, mod }}$ in Equation (4) is written as the difference between the $f_{\text {pav }}$ modelled using high-resolution $f_{\mathrm{tv}}$ and the $f_{\text {pav }}$ modelled using kilometric $\left\langle f_{\mathrm{tv}}\right\rangle_{\mathrm{km}}$ :

$$
\Delta f_{\text {pav }, \bmod }=f_{\text {pav }, \bmod }\left(f_{\mathrm{tv}}\right)-f_{\mathrm{pav}, \bmod }\left(\left\langle f_{\mathrm{tv}}\right\rangle_{\mathrm{km}}\right)
$$

Hence, one obtains:

$$
\Delta f_{\mathrm{pav}, \bmod }=\frac{\mathbf{T}_{\mathbf{v}, \max }-\mathbf{T}_{\mathbf{s}}}{\mathbf{T}_{\mathbf{v}, \max }-\mathbf{T}_{\mathbf{v}, \min }}\left(f_{\mathrm{tv}}-\left\langle f_{\mathrm{tv}}\right\rangle_{\mathrm{km}}\right)
$$

Note that Equation (9) does not use temperature data at fine spatial scales. Projected $f_{\text {pav }}$ is computed in Equation (4) and used in the downscaling 
relationship of Equation (3). The regression coefficient $\mathbf{a}_{\mathbf{1}}^{\text {proj }}$ in Equation (3) is estimated from the projected $f_{\text {pav }}$ estimated at kilometric resolution, which is given by:

$$
f_{\text {pav }, \mathrm{km}}^{\text {proj }}=\left\langle f_{\mathrm{pav}}\right\rangle_{\mathrm{km}}-\frac{\mathbf{T}_{\mathbf{v}, \max }-\mathbf{T}_{\mathbf{s}}}{\mathbf{T}_{\mathbf{v}, \max }-\mathbf{T}_{\mathbf{v}, \min }}\left(\left\langle f_{\mathrm{tv}}\right\rangle_{\mathrm{km}}-\mathbf{f}_{\mathbf{t v}}\right)
$$

with $\mathbf{f}_{\mathbf{t v}}$ being the average of $f_{\mathrm{tv}}$ over the whole study area.

\subsection{Data collection and pre-processing}

The Yaqui experiment was conducted throughout an agricultural season from November 2007 to June 2008 in northwestern Mexico $\left(27.25^{\circ} \mathrm{N}, 109.88^{\circ}\right.$ W). The campaign focused on an irrigated area including mainly wheat, corn, chickpeas and beans. Soil in the top 0-20 $\mathrm{cm}$ was classified as clay with an average of $44 \%$ and $36 \%$ for clay and sand fractions, respectively. The objective of the experiment was to characterize the spatial variability of surface fluxes from the field (hectometric) to kilometric scale. Meteorological data including air temperature, solar radiation, relative humidity and wind speed were monitored throughout the agricultural season at a semi-hourly time step from December 27, 2007 until May 17, 2008. The study area is defined as a $16 \mathrm{~km}$ by $10 \mathrm{~km}$ area (i) containing the Yaqui experimental area, (ii) included in all Formosat and ASTER images, and (iii) delineated to exactly match up the $1 \mathrm{~km}$ resolution MODIS grid.

\subsubsection{Formosat-2 data}

Formosat-2 was launched by the National Space Organization of Taiwan in May 2004 onto a sun-synchronous orbit. The Remote Sensing Instrument (RSI) onboard Formosat-2 provides high-spatial-resolution images ( $8 \mathrm{~m}$ in the 
multispectral mode for nadir viewing) in four spectral bands ranging from $0.45 \mu \mathrm{m}$ (blue) to $0.90 \mu \mathrm{m}$ (near infrared). Unlike other systems operating at high-spatial resolution, Formosat-2/RSI may observe a particular area every day with the same viewing angle. The scenes are 24-km wide (along-track) and 27-km long (across-track). More details can be found in Chern et al. (2008).

Forty-two cloud free Formosat-2/RSI images were collected over the Yaqui area from 15 November 2007 to 6 June 2008. All images were acquired with an off-nadir angle of $12 \pm 1^{\circ}$. Image processing included: (i) absolute geolocation of a cloud-free image against a set of ground control points collected with GPS, (ii) registration of this and other images using an autocorrelation algorithm, (iii) reprojection of data using UTM WGS 1984 12N coordinate system with a sampling interval of $8 \mathrm{~m}$, (iv) atmospheric correction (Hagolle et al., 2008) and (v) re-sampling of $8 \mathrm{~m}$ resolution Formosat-2 red and near-infrared reflectances at $100 \mathrm{~m}$ resolution over the $16 \mathrm{~km}$ by $10 \mathrm{~km}$ study area.

\subsubsection{Biophysical variables derived from Formosat-2 images}

NDVI and surface albedo are computed using $100 \mathrm{~m}$ resolution re-sampled Formosat-2 data. NDVI is the ratio of the difference between near-infrared and red reflectances to their sum. Surface albedo $\alpha$ is estimated as a weighted sum of red and near-infrared reflectances with the coefficients given by Weiss et al. (1999) and validated in Bsaibes et al. (2009).

Fractional photosynthetically active vegetation cover can be estimated using the expression of Gutman and Ignatov (1998):

$$
f_{\mathrm{pav}}=\frac{\mathrm{NDVI}-\mathrm{NDVI}_{\mathrm{s}}}{\mathrm{NDVI}_{\mathrm{pav}}-\mathrm{NDVI}_{\mathrm{s}}}
$$


with $\mathrm{NDVI}_{\text {pav }}$ corresponding to fully covering photosynthetically active vegetation and $\mathrm{NDVI}_{\mathrm{s}}$ to bare soil or to bare soil partially covered by nonphotosynthetically active vegetation. In the current study, $\mathrm{NDVI}_{\mathrm{pav}}$ and $\mathrm{NDVI}_{\mathrm{s}}$ are set to the maximum (0.93) and minimum (0.18) value of the NDVI observed during the agricultural season within the study area.

The fractional vegetation cover $f_{\mathrm{tv}}$ is defined as the surface of total (photosynthetically and non-photosynthetically active) vegetation per soil surface unit. A simple approach is developed to estimate $f_{\mathrm{tv}}$ on a pixel-by-pixel basis from the time series of Formosat-derived $f_{\text {pav }}$ and $\alpha$. As an illustration, Figure 2 plots the typical variations of surface albedo as a function of fractional photosynthetically active vegetation cover for a given $100 \mathrm{~m}$ resolution pixel in the study area. It is apparent that surface albedo increases with fractional photosynthetically active vegetation cover, and keeps increasing when vegetation dries. An interesting feature is visible at the beginning of the agricultural season when the variations of surface albedo are due to the drying of bare soil in between two irrigations, and at the end of the season when constant and high values of surface albedo (up to 0.30) are observed from the harvest date indicating the presence of bright stubble. Formally, fractional vegetation cover is estimated as:

$$
\begin{aligned}
& \text { if } \alpha \leq \alpha\left(f_{\mathrm{pav}, \max }\right), \quad f_{\mathrm{tv}}=\frac{\alpha-\alpha_{\mathrm{s}}}{\alpha_{\mathrm{pav}}-\alpha_{\mathrm{s}}} \\
& \text { if } \alpha>\alpha\left(f_{\mathrm{pav}, \max }\right), \quad f_{\mathrm{tv}}=f_{\mathrm{pav}, \max }
\end{aligned}
$$

with $\alpha\left(f_{\text {pav, max }}\right)$ being the surface albedo observed at the maximum of fractional photosynthetically active vegetation cover $\left(f_{\text {pav, max }}\right), \alpha_{\mathrm{s}}$ the albedo of bare soil, and $\alpha_{\text {pav }}$ the albedo of a fully-covering photosynthetically active canopy. In Equations (12) and (13), $\alpha\left(f_{\text {pav, max }}\right), \alpha_{\mathrm{s}}, \alpha_{\text {pav }}$ and $f_{\text {pav, max }}$ are 
estimated on a pixel-by-pixel basis from the time series of Formosat-2 data. An illustration is presented in Figure 2 for a given pixel. Bare soil albedo $\alpha_{\mathrm{s}}$ is set to the minimum value observed during the agricultural season. The mean and standard deviation of $\alpha_{\mathrm{s}}$ over the study area is 0.080 and 0.016 (20 $\%$ of the mean value), respectively. Green vegetation albedo $\alpha_{\text {pav }}$ is set to the value extrapolated at $f_{\mathrm{pav}}=1$ by assuming a linear relationship between $\alpha$ and $f_{\text {pav }}$ during the growing period. The mean and standard deviation of $\alpha_{\text {pav }}$ over the study area is 0.20 and 0.036 (18\% of the mean value), respectively.

During the growing period, soil moisture may have an impact on the relationship between surface albedo and fractional photosynthetically active vegetation cover in Equation (12). As $\alpha_{\mathrm{s}}$ corresponds to the wet soil albedo, the algorithm tends to overestimate $f_{\mathrm{tv}}$ when soils are relatively dry. However, the successive periods of irrigation and drying and the high-temporal frequency of Formosat-2 data allow clearly identifying the edge corresponding to wet soil. During the senescence period, the impact of soil moisture is rather low because irrigation stops and vegetation cover is maximum. In fact, the relationship in Equation (12) can be applied to the conditions when soils are relatively dry as long as soil albedo does not get values larger than green vegetation albedo. This is generally the case for brown clay or silty soils in agricultural areas, but not for sandy soils.

Figure 3 plots fractional vegetation cover as function of surface albedo for all dates and all the pixels with $\alpha<\alpha\left(f_{\mathrm{pav}, \max }\right)$. The increase of $f_{\mathrm{tv}}$ with $\alpha$ is explained by a value of soil albedo significantly lower than vegetation albedo. Figure 3 indicates that the albedo over bare soil is about 0.08 , which is a typical value for wet clay (e.g. Ten Berge, 1986). The albedo over full- 
cover vegetation ranges from about 0.16 to 0.25 , which are typical values for irrigated and dry crops, respectively (e.g. Campbell and Norman, 1998). The procedure in Equations (12) and (13) would not be adapted for sandy soils having an albedo (about 0.20) larger than the typical value for green crops.

The images of fractional photosynthetically active vegetation cover, surface albedo and fractional vegetation cover are presented in Figure 4 at the beginning (December 30), middle (April 11) and end (May 6) of the agricultural season. They illustrate both the seasonality of canopies throughout the agricultural season and the high variability of vegetation cover within the study area.

\subsubsection{ASTER data}

The ASTER was launched in 1999 on a sunsynchronous platform (NASA's Terra satellite) with 10:30 am descending Equator crossing and a 16-day revisit cycle. The ASTER thermal sensor provides nadir-looking scenes of approximately $60 \mathrm{~km}$ by $60 \mathrm{~km}$. Data are collected on request over specified areas. There are five thermal bands with a $90 \mathrm{~m}$ resolution and centred at $8.30,8.65,9.05,10.60$ and $11.30 \mu \mathrm{m}$. The accuracy in ASTER temperature and emissivity was predicted (Gillespie et al., 1998) and is currently estimated (Jacob et al., 2008; Sabol et al., 2009) as within $1.5 \mathrm{~K}$ and 0.015, respectively.

During the 2007-2008 agricultural season, 7 cloud free ASTER images were collected over the Yaqui area at around 11:00 am local solar time on December 30, February 23, March 10, April 11, April 27, May 6 and May 13. ASTER official products were downloaded from the Earth Observing 
System Data Gateway. They consisted of the $90 \mathrm{~m}$ resolution surface skin temperature (AST08) retrieved by the "temperature and emissivity separation" algorithm (Gillespie et al., 1998; Schmugge et al., 1998a) and projected in UTM WGS 1984 12N. The absolute registration of ASTER data was performed using a background $8 \mathrm{~m}$ resolution Formosat-2 image. Sub-images were extracted over the $16 \mathrm{~km}$ by $10 \mathrm{~km}$ study area and were re-sampled at $100 \mathrm{~m}$ resolution using the bicubic interpolation.

In this study, $100 \mathrm{~m}$ resolution ASTER data are used as a reference to evaluate disaggregation results. To evaluate disaggregation algorithms independently from differences between ASTER and MODIS products, ASTER data are also used to generate kilometric observations which are unbiased against reference temperatures. This is done by linearly averaging highresolution surface temperatures, i.e. without accounting for the nonlinear relationship between physical temperature and emissivity. This choice is motivated by the results of Liu et al. (2006) who compared the temperature aggregated using different scaling approaches and obtained very low differences (maximum difference of $0.2^{\circ} \mathrm{C}$ ).

\subsubsection{MODIS data}

The MODIS/Terra data were collected concurrently with ASTER data with an incidence angle of $7 \pm 1^{\circ}$. MODIS official products consisted of the 928 $\mathrm{m}$ resolution surface skin temperature (MOD11-L2) retrieved by the "generalized split window" algorithm (Wan and Dozier, 1996; Wan et al., 2002) and registered in a sinusoidal projection. The MODIS Reprojection Tool (http://igskmncnwb001.cr.usgs.gov/landdaac/tools/modis/index.asp) was used to project MOD11-L2 data in UTM WGS 1984 12N with a sampling interval 
of $1 \mathrm{~km}$.

As a first assessment of thermal data, the MODIS temperature re-sampled at $1 \mathrm{~km}$ resolution is compared against the ASTER data aggregated at 1 $\mathrm{km}$ resolution in Figure 5. The mean root mean square difference between MODIS and ASTER data is $2.4^{\circ} \mathrm{C}$ for all dates. This is consistent with recent studies reporting a discrepancy between ASTER and MODIS surface temperature of about $3^{\circ} \mathrm{C}$ (Liu et al., 2006, 2007). The same comparison is done at $2 \mathrm{~km}$ resolution by aggregating ASTER and $1 \mathrm{~km}$ re-sampled MODIS data. The $2 \mathrm{~km}$ resolution is chosen arbitrarily as twice the MODIS nadir resolution to investigate the impact of the re-sampling of MODIS data on the difference between MODIS and ASTER products. The mean root mean square difference between $2 \mathrm{~km}$ resolution re-sampled MODIS and ASTER data is $1.8^{\circ} \mathrm{C}$ for all dates. It is suggested that the lower difference between MODIS and ASTER products at $2 \mathrm{~km}$ resolution is mainly due to the resampling of MODIS temperature product. Re-sampling is a necessary step to use data in a given coordinate system. However, it systematically smoothes spatial data, especially over highly heterogeneous areas like Yaqui. Both 1 $\mathrm{km}$ and $2 \mathrm{~km}$ resolution MODIS data sets will be used in the following to assess the impact of the accuracy in MODIS data on disaggregation results.

\subsection{Extreme temperatures extrapolated from MODIS data using ancillary data}

The disaggregation procedure D2 requires an estimate of $\mathbf{T}_{\mathbf{s}, \min }, \mathbf{T}_{\mathbf{s}}$, max, $\mathbf{T}_{\mathbf{v}}$, min and $\mathbf{T}_{\mathbf{v}}$, max. The algorithm for estimating extreme temperatures is derived from learnings brought by Figure 6 .

Figure 6 a plots the space defined by kilometric surface temperature and 
kilometric surface albedo for data on April 27. A polygon is obtained as in Roerink et al. (2000) and Gómez et al. (2005). Note that the relationships between surface temperature and reflectance (or albedo) have been extensively used to develop remote sensing-based energy budget models like SEBAL (Surface Energy Balance Algorithm for Land, Bastiaanssen et al. 1998)) and S-SEBI (Simplified Surface Energy Balance Index, Roerink et al. (2000)) to monitor evapotranspiration at decametric (Jacob et al., 2002; Gómez et al., 2005) and regional (van den Hurk et al., 1997) scale.

Before interpreting the space $T_{\mathrm{km}}-\langle\alpha\rangle_{\mathrm{km}}$ at kilometric resolution, let consider the space defined at high resolution. ASTER temperature is plotted against surface albedo in Figure [6 and against fractional photosynthetically active vegetation cover in Figure [6 for data on a typical day (April 27). It is apparent that the space $T-\alpha$ has a polygonal shape while the space $T-f_{\text {pav }}$ has a mostly triangular shape. In fact, the presence of nonphotosynthetically active vegetation is captured by surface albedo, but not by fractional photosynthetically active vegetation cover. This justifies the use of $T$ - $\alpha$ instead of $T$ - $f_{\text {pav }}$. In Figure 6 , the four edges of the polygon $T$ - $\alpha$ are interpreted as "bare soil" between A and B, "dry surface" between B and C, "full-cover vegetation" between C and D and "wet surface" between $\mathrm{D}$ and A. Correspondence with the vertices of the trapezoid in Moran et al. (1994) is highlighted.

In the case of the disaggregation of MODIS data, high-resolution surface temperature $T$ is assumed to be unknown. Therefore, one needs to develop an approach to extrapolate extreme temperatures from the space $T_{\mathrm{km}}-\langle\alpha\rangle_{\mathrm{km}}$ defined at kilometric resolution. Below is described step-by-step the algo- 
rithm used to estimate $\mathbf{T}_{\mathbf{s}, \boldsymbol{m i n}}, \mathbf{T}_{\mathbf{s}, \max }, \mathbf{T}_{\mathbf{v}}$, $\min$ and $\mathbf{T}_{\mathbf{v}}$, max from Figure 6h:

- $\mathbf{T}_{\mathbf{v}, \min }$ is set to the air temperature $T_{\mathrm{a}}$ measured in the Yaqui area at the time of ASTER overpass.

- $\mathbf{T}_{\mathbf{s}, \text { min }}$ is defined by the intersect between the line of wet surface and the line of bare soil. The line of bare soil is defined as a vertical line at $\langle\alpha\rangle_{\mathrm{km}}=\alpha_{\mathrm{min}}$, with $\alpha_{\min }$ being the minimum surface albedo within the study area. The line of wet surface passes through $\left(\left\langle\alpha_{\text {pav }}\right\rangle, T_{\mathrm{a}}\right)$ with $\left\langle\alpha_{\text {pav }}\right\rangle$ being the mean photosynthetically active vegetation albedo within the study area. The line of wet surface has a slope such as all points are kept above the wet edge.

- $\mathbf{T}_{\mathbf{s}, \text { max }}$ is defined by the intersect between the line of dry surface and the line of bare soil. The line of dry surface passes through the point with maximum surface temperature and has a slope such as all points are kept below the dry edge.

- $\mathbf{T}_{\mathbf{v}, \text { max }}$ is defined as the ordinate of the dry line at $\langle\alpha\rangle_{\mathrm{km}}=\alpha_{\max }$, with $\alpha_{\max }$ being the maximum surface albedo within the study area.

To strengthen the approach, the slope of the wet edge and that of the dry edge are assumed to be the same. This is based on the observation that the lines $\mathrm{AD}$ and $\mathrm{BC}$ in the space $T-\alpha$ are practically parallel. This is also based on a theoretical consideration. Menenti et al. (1989) demonstrated that the slope $\partial \alpha / \partial T$ is proportional to the aerodynamic exchange resistance. Consequently, if the aerodynamic resistance over full-cover non-photosynthetically 
active vegetation is assumed to be the same as that over full-cover photosynthetically active vegetation as in Bastiaanssen et al. (1998), then AD and $\mathrm{BC}$ are theoretically parallel. On an algorithmic point of view, the slope of wet and dry lines is estimated separately, and the mean value is applied to both edges.

\subsection{Projection}

The usefulness of the projection technique is first assessed by plotting in

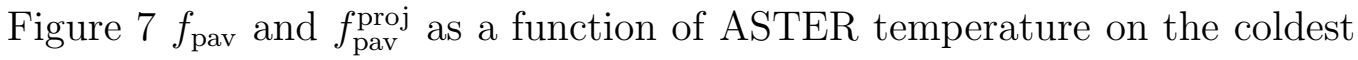

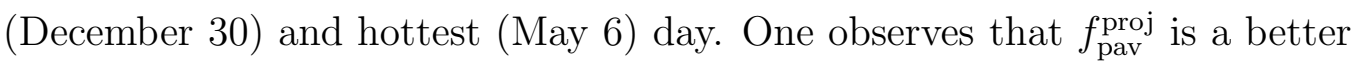
indicator of the variability of surface temperature than $f_{\mathrm{pav}}$. In particular, the projection improves the correlation coefficient between fractional photosynthetically active vegetation cover and ASTER temperature from 0.72 to 0.76 on December 30 and from 0.70 to 0.73 on May 6 .

\section{Application to Aggregated ASTER Data}

Disaggregation algorithms D0, D1 and D2 are applied to the ASTER data aggregated at MODIS resolution, and results are compared against ASTER data. The application to aggregated ASTER data implicitly assumes that low-resolution observations are perfectly accurate with respect to high-resolution ASTER data. This is practical to evaluate disaggregation

results independently from uncertainties in low-resolution data (Agam et al., 2007). 


\section{1. $1 \mathrm{~km}$ resolution aggregated ASTER data}

Figure 8 presents the $16 \mathrm{~km}$ by $10 \mathrm{~km}$ images on the coldest (December 30) and hottest (May 6) day of the temperature disaggregated at 100 $\mathrm{m}$ resolution by D0, D1 and D2 and the ASTER temperature re-sampled at $100 \mathrm{~m}$ resolution. The images obtained by D1 and D2 are first compared with ASTER images. One observes that the distribution of temperature is generally better restituted with D2 than with D1. The images obtained by D1 and D2 are then compared with those obtained by D0. One observes that the "boxy artifact" at $1 \mathrm{~km}$ resolution is more apparent for D1 than for D2. The notion of boxy artifact was first introduced by Agam et al. (2007) to describe the low-resolution grid that is still apparent on disaggregated images. In Agam et al. (2007), the boxy artifact was attributed to the variability at low resolution of the surface conditions that are not accounted for in the disaggregation. In the case of D2, it is suggested that the insertion of fractional non-photosynthetically active vegetation cover improves the sensitivity of the disaggregation algorithm, then reduces the boxy artifact.

Table 1 lists the root mean square difference, correlation coefficient and slope between disaggregated and ASTER temperature for each of the seven ASTER overpass dates. The mean fractional non-photosynthetically active vegetation cover $\left\langle f_{\mathrm{tv}}-f_{\mathrm{pav}}\right\rangle$ is also listed. Results indicate that both D1 and D2 systematically perform better than D0. They also indicate that the slope between disaggregated and ASTER temperature is systematically closer to 1 with D2 than with D1. However, the performance of D2 relatively to D1

seems to vary from date to date. In fact, the performance of D2 is intimately related to the amount of non-photosynthetically active vegetation. One ob- 
serves in Table 1 that disaggregation results are more accurate with D1 on the three dates when the mean fractional non-photosynthetically active vegetation cover over the study area is lower than 0.06 . This was expected since the representation of the impact of non-photosynthetically active vegetation when the fraction of non-photosynthetically active vegetation is low should decrease the signal to noise ratio within the disaggregation, and thus make the uncertainty in disaggregation output increase. When selecting the four dates with a mean fractional non-photosynthetically active vegetation cover larger than 0.10 , the mean correlation coefficient between disaggregated and ASTER temperature is increased from 0.75 to 0.81 , and the mean slope is increased from 0.60 to 0.77 . The systematic increase in the slope is notably visible in the scatterplots of Figure 9.

Although D2 is found to be more robust than D1, the error on disaggregated temperature is still about $3^{\circ} \mathrm{C}$. This error is notably explained by the variability of soil temperature, which was not accounted for in this study. Also, the performance of D2 seems to be weaker on May 6 and 13 (see Table

11). Note that the scheme for estimating fractional vegetation cover in Equation (12) may not be valid at the end of the season when leaves wilt and in some instances fall off.

\section{2. $2 \mathrm{~km}$ resolution aggregated ASTER data}

The disaggregation algorithms D0, D1 and D2 are now applied to the ASTER data aggregated at $2 \mathrm{~km}$ resolution and results are presented in Table 2 for the four dates with a mean fractional non-photosynthetically active vegetation cover larger than 0.10 . As the number of $2 \mathrm{~km}$ resolution pixels within the study area is much reduced as compared to $1 \mathrm{~km}$ resolution 
pixels, the estimation of extreme temperatures in Section 2.3 is still based on $1 \mathrm{~km}$ resolution data for representativity reasons. When using the 2 $\mathrm{km}$ instead of $1 \mathrm{~km}$ resolution temperature as input to the disaggregation algorithms, the performance of D0, D1, and D2 is systematically degraded on each date. The mean correlation coefficient between disaggregated and ASTER temperature is decreased from 0.75 to 0.68 and from 0.81 to 0.77 for D1 and D2, respectively. The slope is also decreased for D1 from 0.60 to 0.52 but not for D2. The poorer results obtained using the ASTER data aggregated at $2 \mathrm{~km}$ resolution is due to the increase of the sub-pixel variability at $2 \mathrm{~km}$ resolution. This point is illustrated by the increase of the error in the temperature disaggregated by $\mathrm{D} 0$ from $3.7^{\circ} \mathrm{C}$ to $4.1^{\circ} \mathrm{C}$ when using data aggregated at $1 \mathrm{~km}$ and $2 \mathrm{~km}$ resolution, respectively. The increase of disaggregation error when increasing the gap between high and low resolution was already mentioned in Merlin et al. (2009).

The aggregation of low-resolution data before the disaggregation makes the slope between disaggregated and ASTER data decrease. In order words, aggregating low-resolution data reduces the sensitivity of the disaggregation algorithm. However, the inclusion of an additional variable (fractional non-photosynthetically active vegetation in our case) in the disaggregation increases the sensitivity of D2, and thus makes the slope increase. One consequence is that D2 is more robust with respect to the resolution of lowresolution data than D0 and D1. In particular, the slope between disaggregated and ASTER temperature is approximately unchanged for D2 when using $1 \mathrm{~km}$ and $2 \mathrm{~km}$ resolution aggregated ASTER data. 


\section{Application to MODIS Data}

\section{1. $1 \mathrm{~km}$ resolution re-sampled MODIS data}

Disaggregation algorithms are first applied to the MODIS data re-sampled at $1 \mathrm{~km}$ resolution. Statistical results for all dates with a mean fractional non-photosynthetically active vegetation cover larger than 0.10 are listed in Table 3. The mean root mean square difference between disaggregated and ASTER temperature is $4.0^{\circ} \mathrm{C}$ and $3.8^{\circ} \mathrm{C}$ for $\mathrm{D} 1$ and $\mathrm{D} 2$, respectively. The use of MODIS data instead of aggregated ASTER data results in an increase by about $1^{\circ} \mathrm{C}$ of the mean error. The error increase is attributed to the discrepancy between MODIS and ASTER data. In particular, the root mean square difference $\left(3.8^{\circ} \mathrm{C}\right.$ for D2) is approximately equal to the square root of the sum of the mean square difference between MODIS and ASTER temperature $\left(2.4^{\circ} \mathrm{C}\right)$ and the mean square error in the temperature disaggregated using aggregated ASTER temperature $\left(2.8^{\circ} \mathrm{C}\right)$. The negative mean differences between disaggregated and ASTER temperature are not caused by the disaggregation algorithms but by the difference between MODIS and ASTER products. In terms of algorithmic performance, D1 and D2 are still more accurate than D0 and D2 is more accurate than D1 consistent with the results obtained using aggregated ASTER data.

\section{2. $2 \mathrm{~km}$ resolution re-sampled MODIS data}

It is reminded that $2 \mathrm{~km}$ resolution re-sampled MODIS data are closer to ASTER data than $1 \mathrm{~km}$ resolution re-sampled MODIS data. As stated earlier, the difference between MODIS and ASTER products may be due to image co-registration error and to the algorithm used to derive land surface 
temperature. To assess the impact of the accuracy in re-sampled MODIS data on disaggregation results, algorithms D0, D1, and D2 are now applied to $2 \mathrm{~km}$ resolution re-sampled MODIS data. Results for all dates with a mean fractional non-photosynthetically active vegetation cover larger than 0.10 are presented in Table 4. When using the $2 \mathrm{~km}$ instead of $1 \mathrm{~km}$ resolution MODIS temperature as input to the disaggregation algorithms, statistical results are improved for D1 and D2. The decrease in the mean error for D1 and D2 is associated with an increase of the mean correlation coefficient and an increase of the mean slope. In fact, because MODIS data are closer to ASTER data at $2 \mathrm{~km}$ than at $1 \mathrm{~km}$ resolution, the aggregation of MODIS data from $1 \mathrm{~km}$ to $2 \mathrm{~km}$ has two opposite effects on disaggregation results. On the one hand, aggregation increases the gap between low and high resolution, and thus amplifies sub-pixel variabilities and associated disaggregation errors. On the other hand, aggregation reduces random uncertainties in MODIS data and consequently increases the disaggregation accuracy. Under the conditions that prevail in this study, the gain in accuracy by aggregating MODIS data at $2 \mathrm{~km}$ resolution is superior to the loss in accuracy due to the increase of sub-pixel variabilities, so that the disaggregation is actually improved by using $2 \mathrm{~km}$ resolution re-sampled MODIS data.

\section{Sensitivity Analysis}

\subsection{Input data}

Application of disaggregation algorithm D2 requires a number of parameters determined from both high-resolution shortwave data and low-resolution thermal infrared data. These include albedo values for the estimation of the 
fractional total vegetation cover, and albedo and extreme temperatures for the projection of fractional photosynthetically active vegetation cover. To assess the impact on disaggregation results of uncertainties in these parameters, a sensitivity analysis is conducted by varying $\alpha_{\mathrm{s}}, \alpha_{\text {pav }}, \mathbf{T}_{\mathbf{s}, \boldsymbol{m i n}}, \mathbf{T}_{\mathbf{s}, \max }$, $\mathbf{T}_{\mathbf{v}}$, min and $\mathbf{T}_{\mathbf{v}}$, max. In practice, D2 is applied to three different data sets A, B and C. Data set A is the same as that used in Section 3.1: $f_{\mathrm{tv}}$ is derived from Equation (12) by using the parameters $\alpha_{\mathrm{s}}$ and $\alpha_{\text {pav }}$ derived at high-resolution from the time series of Formosat-2 data and $f_{\text {pav }}^{\text {proj }}$ is derived from Equation (9) by using the extreme temperatures derived from the space $T_{\mathrm{km}}-\langle\alpha\rangle_{\mathrm{km}}$ at $1 \mathrm{~km}$ resolution. Data set $\mathrm{B}$ is identical to $\mathrm{A}$ except that $f_{\mathrm{tv}}$ is derived by using $\left\langle\alpha_{\mathrm{s}}\right\rangle$ and $\left\langle\alpha_{\text {pav }}\right\rangle$, the soil and photosynthetically active vegetation albedo averaged within the study area respectively. The root mean square difference between $\alpha_{\mathrm{s}}$ and $\left\langle\alpha_{\mathrm{s}}\right\rangle$ and between $\alpha_{\text {pav }}$ and $\left\langle\alpha_{\text {pav }}\right\rangle$ is 0.016 and 0.036 , respectively. Data set $\mathrm{C}$ is identical to $\mathrm{A}$ expect that

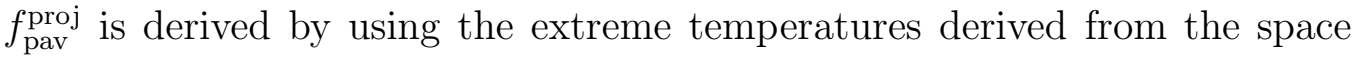
$T-\alpha$ at $100 \mathrm{~m}$ resolution (as in Figure 6b). The root mean square difference between the extreme temperatures estimated from the space $T_{\mathrm{km}}-\langle\alpha\rangle_{\mathrm{km}}$ at 1 $\mathrm{km}$ resolution and those estimated from the space $T-\alpha$ at $100 \mathrm{~m}$ resolution are $1.8,2.7,4.4$ and $2.8^{\circ} \mathrm{C}$ for $\mathbf{T}_{\mathbf{v}, \min }, \mathbf{T}_{\mathbf{s}, \min }, \mathbf{T}_{\mathbf{v}, \max }$ and $\mathbf{T}_{\mathbf{s}, \max }$ respectively. The disaggregation results obtained with data set A, B and C are presented in Table 5 in terms of root mean square difference, correlation coefficient and slope between disaggregated and ASTER temperatures. One observes that the statistical results obtained with data set A are in general slightly degraded with data set B and slightly improved with data set C. However, the difference between data sets is relatively low compared to the improve- 
ment associated with the use of D2 instead of D1 and D0. Consequently, the sensitivity analysis indicates that D2 is relatively stable with respect to uncertainties in input parameters.

\subsection{Formulation of fractional photosynthetically active vegetation cover}

Fractional photosynthetically active vegetation cover is required in both D1 and D2. In this study, $f_{\text {pav }}$ is estimated using the expression from Gutman and Ignatov (1998) presented in Equation (11). As many other expressions have been developed, one needs to evaluate the impact of a change in the formulation of $f_{\text {pav }}$ on disaggregation results. For instance, Baret et al. (1995) expressed fractional photosynthetically active vegetation cover as:

$$
f_{\text {pav }}=1-\left(\frac{\mathrm{NDVI}_{\mathrm{pav}}-\mathrm{NDVI}}{\mathrm{NDVI}_{\mathrm{pav}}-\mathrm{NDVI}_{\mathrm{s}}}\right)^{0.62}
$$

and Carlson and Riplev (1997) as:

$$
f_{\mathrm{pav}}=\left(\frac{\mathrm{NDVI}-\mathrm{NDVI}_{\mathrm{s}}}{\mathrm{NDVI}_{\mathrm{pav}}-\mathrm{NDVI}_{\mathrm{s}}}\right)^{2}
$$

The three formulations from Gutman and Ignatov (1998) (GI98), Baret et al. (1995) (B95) and Carlson and Riplev (1997) (CR97) are implemented in D1 and D2 and disaggregation algorithms are applied to data set A. In each case, the root mean square difference, correlation coefficient and slope between disaggregated and ASTER temperatures are presented in Table 6. One observes that both GI98 and B95 are approximately equivalent in terms of disaggregation performance, while errors are slightly increased with CR97. The performance of D2 is generally superior to that of D1, regardless of the formulation chosen for $f_{\text {pav }}$. Therefore, the differentiation between photosynthetically and non-photosynthetically active vegetation cover has a stronger 
impact on disaggregated temperature than the choice in the formulation of fractional photosynthetically active vegetation cover.

\section{Conclusion}

A new disaggregation procedure of kilometric thermal data is developed to account for the status of vegetation. It is based on a time series of Formosat-derived fractional (photosynthetically and non-photosynthetically active) vegetation cover. The methodology is tested over a $16 \mathrm{~km}$ by 10 $\mathrm{km}$ irrigated cropping area in northwestern Mexico during the 2007-2008 agricultural season. On seven dates, kilometric surface temperature is disaggregated at $100 \mathrm{~m}$ resolution, and disaggregated temperature is subsequently compared against concurrent ASTER data.

The disaggregation approach is first applied to the ASTER data aggregated at MODIS resolution $(1 \mathrm{~km})$. Statistical results indicate that the new methodology is more robust than the classical one, and is always more accurate when fractional non-photosynthetically active vegetation cover is larger than 0.10 . The mean correlation coefficient and slope between disaggregated and ASTER temperature is increased from 0.75 to 0.81 and from 0.60 to 0.77 , respectively. The disaggregation algorithm is then applied to real MODIS data. The error on disaggregated temperature is increased by $1^{\circ} \mathrm{C}$, which

corresponds to the difference evaluated at $1 \mathrm{~km}$ resolution between ASTER and MODIS data. The approach is also tested using the MODIS data resampled at $2 \mathrm{~km}$ resolution. Aggregation reduces random errors in MODIS data and consequently increases the disaggregation accuracy.

Although the new methodology is found to be more robust than the 
classical one, the disaggregation error is still about $3^{\circ} \mathrm{C}$, which corresponds to an error in evapotranspiration of about $150 \mathrm{~W} \mathrm{~m}^{-2}$ (Kalma et al., 2008). This error could be partly explained by the variability of surface temperature for different values of surface soil moisture. The integration of microwavederived soil moisture into the disaggregation procedure is part of ongoing research. Before any robust disaggregation method is developed, monitoring water fluxes over highly heterogeneous agricultural areas will rely on thermal remote sensing at Landsat scale.

\section{Acknowledgments}

The participants of the Yaqui 2007-2008 experiment are gratefully acknowledged. The collection and pre-processing of Advanced Spaceborne and Emission Reflection Radiometer (ASTER) and Formosat-2/RSI data have been made possible thanks to the "Programme National de Télédétection Spatiale" and the CNES program "Terre Océan Surface Continentale Atmosphère". This work was funded by the European Commission (FP6, PLEIADeS project) and by the Centre National de la Recherche Scientifique. 


\section{References}

Agam, N., Kustas, W. P., Anderson, M. C., Li, F., Neale, C. M. U., 2007. A vegetation index based technique for spatial sharpening of thermal imagery. Remote Sens. Environ. 107, 545-558.

Anderson, M. C., Norman, J. M., Diak, G. R., Kustas, W. P., Mecikalski, J. R., 1997. A two-source time-integrated model for estimating surface fluxes using thermal infrared remote sensing. Remote Sens. Environ. 60, $195-216$.

Anderson, M. C., Norman, J. M., Mecikalski, J. R., Otkin, J. A., Kustas, W. P., 2007. A climatological study of evapotranspiration and moisture stress across the continental united states based on thermal remote sensing: 2. surface moisture climatology. J. Geophys. Res. 112 (D11112), doi:10.1029/2006JD007507.

Baret, F., Clevers, J. G. P. W., Steven, M. D., 1995. The robustness of canopy gap fraction estimates from red and near-infrared reflectances: A comparison of approaches. Remote Sens. Environ. 54, 141-151.

Bastiaanssen, W. G. M., Menenti, M., Feddes, R. A., Holtslag, A. A. M., 1998. A remote sensing surface energy balance algorithm for land (SEBAL) 1. Formulation. J. Hydrology 212-213, 198-212.

Boulet, G., Chehbouni, A., Gentine, P., Duchemin, B., Ezzahar, J., Hadria, R., 2007. Monitoring water stress using time series of observed to unstressed surface temperature difference. Agri. For. Meteorol. 146, 157-172. 
Bsaibes, A., Courault, D., Baret, F., Weiss, M., Olioso, A., Jacob, F., Hagolle, O., Marloie, O., Bertrand, N., Desfond, V., Kzemipour, F., 2009. Albedo and LAI estimates from FORMOSAT-2 data for crop monitoring. Remote Sens. Environ. 113, 716-729, doi:10.1016/j.rse.2008.11.014.

Campbell, G., Norman, J., 1998. An introduction to environmental biophysics, 2nd Edition. Springer, New York, USA.

Carlson, T. N., Ripley, D. A., 1997. On the relationship between NDVI, fractional vegetation cover and leaf area index. Remote Sens. Environ. 62, $241-252$.

Chern, J.-S., Ling, J., Weng, S.-L., 2008. Taiwan's second remote sensing satellite. Acta Astronautica 63 (11-12), 1305-1311, doi:10.1016/j.actaastro.2008.05.022.

Courault, D., Jacob, F., Benoit, V., Weiss, M., Marloie, O., Hanocq, J. F., Fillol, E., Olioso, A., Dedieu, G., Gouaux, P., Gay, M., French, A., 2009. Influence of agricultural practices on micrometeorological spatial variations at local and regional scales. Int. J. Remote Sens. 30 (5), 1183-1205.

Duchemin, B., Hagolle, O., Mougenot, B., Benhadj, I., Hadria, R., Simonneaux, V., Ezzahar, J., Hoedjes, J., Khabba, S., Kharrou, M. H., Boulet, G., Dedieu, G., Er-Raki, S., Escadafal, R., Olioso, A., Chehbouni, A. G., 2008. Agrometeorological study of semi-arid areas: an experiment for analysing the potential of time series of FORMOSAT-2 images (Tensift-Marrakech plain). Int. J. Remote Sens. 29 (17), 5291-5299, doi:10.1080/01431160802036482. 
Er-Raki, S., Chehbouni, A., Hoedjes, J., Ezzahar, J., Duchemin, B., Jacob, F., 2008. Improvement of FAO-56 method for olive orchards through sequential assimilation of thermal infrared-based estimates of ET. Agr. Water Manag. 95 (3), 309-321.

French, A. N., Jacob, F., Anderson, M. C., Kustas, W. P., Timmermans, W., Gieske, A., Su, Z., Su, H., McCabe, M. F., Li, F., Prueger, J., Brunsell, N., 2005. Surface energy fluxes with the Advanced Spaceborne Thermal Emission and Reflection radiometer (ASTER) at the Iowa 2002 SMACEX site (USA). Remote Sens. Environ. 99 (1-2), 55-65, doi:10.1016/j.rse.2005.05.015.

Gillespie, A., Rokugawa, S., Matsunaga, T., Cothern, S., Hook, S., Khale, A., 1998. A temperature and emissivity separation algorithm for Advanced Spaceborne Thermal Emission and Reflection (ASTER) images. IEEE Trans. Geosci. Remote Sens. 36, 1113-1126.

Gómez, M., Olioso, A., Sobrino, J. A., Jacob, F., 2005. Retrieval of evapotranspiration over the Alpilles/ReSeDA experimental site using airborne POLDER sensor and a thermal camera. Remote Sens. Environ. 96, 399408.

Gutman, G., Ignatov, A., 1998. The derivation of the green vegetation fraction from NOAA/AVHRR data for use in numerical weather prediction models. Int. J. Remote Sens. 19, 1533-1543.

Hadria, R., Duchemin, B., Jarlan, L., Dedieu, G., Baup, F., Khabba, S., Olioso, A., Le Toan, T., 2010. Potentiality of optical and radar satellite 
data at high spatio-temporal resolutions for the monitoring of irrigated wheat crops in Morocco. Int. J. Appl. Earth Obs. Geoinf. 12, S32-S37, doi:10.1016/j.jag.2009.09.003.

Hagolle, O., Dedieu, G., Mougenot, B., Debaeker, V., Duchemin, B., Meygret, A., 2008. Correction of aerosol effects on multitemporal images acquired with constant viewing angles: Application to Formosat-2 images. Remote Sens. Environ. 112, 1689-1701, doi:10.1016/j.rse.2007.08.016.

Inamdar, A. K., French, A., 2009. Disaggregation of GOES land surface temperatures using surface emissivity. Geophys. Res. Lett. 36 (D02408), doi:10.1029/2008GL036544.

Inamdar, A. K., French, A., Hook, S., Vaughan, G., Luckett, W., 2008. Land surface temperature retrieval at high spatial and temporal resolutions over the southwestern United States. J. Geophys. Res. 113 (D07107), doi:10.1029/2007JD009048.

Jackson, R. D., Idso, S. B., Reginato, R. J., Pinter, P. J., 1981. Canopy temperature as a crop water stress indicator. Water Resour. Res. 17 (4), $1133-1138$.

Jacob, F., Olioso, A., Gu, X. F., Su, Z., Seguin, B., 2002. Mapping surface fluxes using airborne visible, near infrared, thermal infrared remote sensing data and a spatialized surface energy balance model. Agronomie 22, 669680 .

Jacob, F., Schmugge, T., Olioso, A., Courault, D., French, A., Ogawa, K., Petitcolin, F., Chehbouni, G., Pinheiro, A., Privette, J., 2008. Modeling 
and inversion in thermal infrared remote sensing over vegetated land surfaces. Advances in Land Remote Sensing. Vol. 10. S. Liang (ed.), Springer.

Kalma, J. D., McVicar, T. R., McCabe, M. F., 2008. Estimating land surface evaporation: a review of methods using remotely sensed surface temperature data. Surv. Geophys. 29 (4-5), 421-469, doi:10.1007/s10712-008-9037Z.

Kerr, Y. H., Waldteufel, P., Wigneron, J.-P., Martinuzzi, J.-M., Font, J., Berger, M., 2001. Soil moisture retrieval from space: the soil moisture and ocean salinity (SMOS) mission. IEEE Trans. Geosci. Remote Sens. 39, 1729-1735.

Kustas, W. P., Norman, J. M., Anderson, M. C., French, A. N., 2003. Estimating subpixel surface temperatures and energy fluxes from the vegetation index-radiometric temperature relationship. Remote Sens. Environ. 85, 429-440.

Liu, Y., Hiyama, T., Yamaguchi, Y., 2006. Scaling of land surface temperature using satellite data: a case examination on ASTER and MODIS products over a heterogeneous terrain area. Remote Sens. Environ. 105, $115-128$.

Liu, Y., Yamaguchi, Y., Ke, C., 2007. Reducing the discrepancy between ASTER and MODIS land surface temperature products. Sensors 7, 30433057.

Menenti, M., Bastiaanssen, W., van Eick, D., Abd el Karim, M. A., 1989. Linear relationships between surface reflectance and temperature and their 
application to map actual evaporation of groundwater. Adv. Space Res. 9 (1), 165-176.

Merlin, O., Al Bitar, A., Walker, J. P., Kerr, Y., 2009. A sequential model for disaggregating near-surface soil moisture observations using multiresolution thermal sensors. Remote Sens. Environ. 113 (10), 2275-2284, doi:10.1016/j.rse.2009.06.012.

Merlin, O., Al Bitar, A., Walker, J. P., Kerr, Y., 2010. An improved algorithm for disaggregating microwave-derived soil moisture based on red, near-infrared and thermal-infrared data. Remote Sens. Environ.Doi:10.1016/j.rse.2010.05.007.

Merlin, O., Chehbouni, G., 2004. Different approaches in estimating heat flux using dual angle observations of radiative surface temperature. IEEE Trans. Geosci. Remote Sens. 25 (1), 275-289.

Merlin, O., Chehbouni, G., Kerr, Y., Goodrich, D., 2006. A downscaling method for distributing surface soil moisture within a microwave pixel: Application to the Monsoon'90 data. Remote Sens. Environ. 101, 379-389.

Merlin, O., Chehbouni, G., Kerr, Y., Njoku, E. G., Entekhabi, D., 2005. A combined modeling and multi-spectral/multi-resolution remote sensing approach for disaggregation of surface soil moisture: Application to SMOS configuration. IEEE Trans. Geosci. Remote Sens. 43 (9), 2036-2050.

Merlin, O., Chehbouni, G., Walker, J. P., Panciera, R., Kerr, Y., 2008. A simple method to disaggregate passive microwave based soil moisture. 
IEEE Trans. Geosc. Remote Sens., SMOS Special Issue 46 (3), 786-796, doi:10.1109/TGRS.2007.914807.

Moran, M. S., Clarke, T. R., Inoue, Y., Vidal, A., 1994. Estimating crop water deficit using the relation between surface-air temperature and spectral vegetation index. Remote Sens. Environ. 49, 246-263.

Nishida, K., Nemani, R. R., Running, S. W., Glassy, J. M., 2003. An operational remote sensing algorithm of land surface evaporation. J. Geophys. Res. 108 (D9), doi:10.1029/2002JD002062.

Norman, J. M., Anderson, M. C., Kustas, W. P., French, A. N., Mecikalski, J., Torn, R., Diak, G. R., Schmugge, T. J., Tanner, B. C. W., 2003. Remote sensing of surface energy fluxes at 10-m pixel resolutions. Water Resour. Res. 39 (8), 1221, doi:10.1029/2002WR001775.

Norman, J. M., Divakarla, M., Goel, N. S., 1995. Algorithms for extracting information from remote Thermal-IR observations of the Earth's surface. Remote Sens. Environ. 51, 157-168.

Roerink, G. J., Su, Z., Menenti, M., 2000. S-SEBI: a simple remote sensing algorithm to estimate the surface energy balance. Phys. Chem. Earth 25 (2), 147-157.

Sabol, D. E., Gillespie, A. R., Abbott, E., Yamada, G., 2009. Field validation of the ASTER temperature-emissivity separation algorithm. Remote Sens. Environ. 113, 2328-2344, doi:10.1016/j.rse.2009.06.008.

Schmugge, T. J., Hook, S. J., Coll, C., 1998a. Recovering surface temperature 
and emissivity from thermal infrared multispectral data. Remote Sens. Environ. 65, 121-131.

Schmugge, T. J., Kustas, W. P., Humes, K. S., 1998b. Monitoring land surface fluxes using ASTER observations. IEEE Trans. Geosci. Remote Sens. 36 (5), 1421-1430.

Seguin, B., Becker, F., Phulpin, T., Gu, X. F., Guyot, G., Kerr, Y., King, C., Lagouarde, J. P., Ottlé, C., Stoll, M. P., Tabbagh, A., Vidal, A., 1999. IRSUTE: a minisatellite project for land surface heat flux estimation from field to regional scale. Remote Sens. Environ. 68, 357-369.

Sellers, P. J., Meeson, B. W., Hall, F. G., Asrar, G., Murphy, R. E., Schiffer, R. A., Bretherton, F. P., Dickinson, R. E., Ellingson, R. G., Field, C. B., Huemmrich, K. F., Justice, C. O., Melack, J. M., Roulet, N. T., Schimel, D. S., Try, P. D., 1995. Remote sensing of the land surface for studies of global change : models-algorithms-experiments. Remote Sens. Environ. $51,3-26$.

Shuttleworth, W. J., Wallace, J. S., 1985. Evaporation from sparse canopiesan energy combination theory. Q. J. R. Meteorol. Soc. 111, 839-855.

Stisen, S., Sandholt, I., Nørgaard, A., Fensholt, R., Jensen, K. H., 2008. Combining the triangle method with thermal inertia to estimate regional evapotranspiration - Applied to MSG-SEVERI data in the Senegal River basin. Remote Sens. Environ. 112, 1242-1255.

Ten Berge, H., 1986. Heat and wave transfer at the bare soil surface. Aspects 
affecting thermal imagery. PhD Thesis, Wagenigen Univ., The Netherlands.

van den Hurk, B. J. J. M., Bastiaanssen, W. G. M., Pelgrum, H., van Meijgaard, E., 1997. A new methodology for assimilation of initial soil moisture fields in weather prediction models using Meteosat and NOAA data. J. Appl. Meteorol. 36, 1271-1283.

Wan, Z., Dozier, J., 1996. A generalized split-window algorithm for retrieving land-surface temperature from space. IEEE Trans. Geosci. Remote Sens. 34, 892-905.

Wan, Z., Zhang, Y., Zhang, Q., Li, Z.-L., 2002. Validation of the land-surface temperature products retrieved from Terra Moderate Resolution Imaging Spectroradiometer data. Remote Sens. Environ. 83, 163-180.

Weiss, M., Baret, F., Leroy, M., Begué, A., Hautecoeur, O., Santer, R., 1999. Hemispherical reflectance and albedo estimates from the accumulation of across track sun synchroneous satellite data. J. Geophys. Res. 104, 221232. 
Table 1: The ASTER temperature aggregated at $1 \mathrm{~km}$ resolution is disaggregated at $100 \mathrm{~m}$ resolution by D0, D1, and D2, and disaggregated temperature is compared to $100 \mathrm{~m}$ resolution ASTER temperature in terms of root mean square difference (RMSD), correlation coefficient (R) and slope. The regression coefficients $\mathbf{a}_{\mathbf{1}}$ and $\mathbf{a}_{\mathbf{1}}^{\text {proj }}$ and the mean fractional nonphotosynthetically active vegetation cover $\left\langle f_{\mathrm{tv}}-f_{\text {pav }}\right\rangle$ are also indicated for each date. The four dates with $\left\langle f_{\mathrm{tv}}-f_{\text {pav }}\right\rangle>0.10$ are highlighted in bold.

\begin{tabular}{|c|c|c|c|c|c|c|c|c|c|c|c|c|}
\hline \multirow[b]{2}{*}{ Date } & \multicolumn{3}{|c|}{$\operatorname{RMSD}\left({ }^{\circ} \mathrm{C}\right)$} & \multicolumn{3}{|c|}{$\mathrm{R}(-)$} & \multicolumn{3}{|c|}{ Slope (-) } & \multirow{2}{*}{$\begin{array}{c}\mathbf{a}_{1} \\
\left({ }^{\circ} \mathrm{C}\right)\end{array}$} & \multirow{2}{*}{$\begin{array}{l}\mathrm{a}_{1}^{\text {proj }} \\
\left({ }^{\circ} \mathrm{C}\right)\end{array}$} & \multirow{2}{*}{$\begin{array}{c}\left\langle f_{\mathrm{tv}}-f_{\mathrm{pav}}\right\rangle \\
(-)\end{array}$} \\
\hline & D0 & D1 & D2 & D0 & D1 & D2 & D0 & D1 & D2 & & & \\
\hline Dec 30 & 2.66 & 1.90 & 1.71 & 0.54 & 0.80 & 0.85 & 0.29 & 0.68 & 0.81 & -9.6 & -6.6 & 0.21 \\
\hline Feb 23 & 3.69 & 2.22 & 2.42 & 0.56 & 0.87 & 0.85 & 0.31 & 0.81 & 0.82 & -15 & -4.9 & 0.04 \\
\hline Mar 10 & 3.88 & 1.83 & 2.21 & 0.59 & 0.93 & 0.90 & 0.34 & 0.92 & 0.93 & -18 & -4.4 & 0.04 \\
\hline Apr 11 & 4.83 & 3.00 & 3.18 & 0.61 & 0.88 & 0.86 & 0.37 & 0.84 & 0.86 & -22 & -15 & 0.06 \\
\hline Apr 27 & 4.69 & 3.54 & 3.52 & 0.63 & 0.81 & 0.84 & 0.39 & 0.74 & 0.90 & -23 & -20 & 0.36 \\
\hline May 6 & 3.71 & 3.40 & 3.07 & 0.60 & 0.68 & 0.78 & 0.37 & 0.48 & 0.78 & -13 & -17 & 0.62 \\
\hline May 13 & 3.54 & 3.15 & 2.84 & 0.61 & 0.71 & 0.77 & 0.38 & 0.49 & 0.58 & -10 & -14 & 0.69 \\
\hline All & 3.65 & 3.00 & 2.78 & 0.60 & 0.75 & 0.81 & 0.36 & 0.60 & 0.77 & -16 & -12 & 0.47 \\
\hline
\end{tabular}


Table 2: The ASTER temperature aggregated at $2 \mathrm{~km}$ resolution is disaggregated at $100 \mathrm{~m}$ resolution by D0, D1, and D2, and disaggregated temperature is compared to $100 \mathrm{~m}$ resolution ASTER temperature in terms of root mean square difference (RMSD), correlation coefficient (R) and slope. The regression coefficients $\mathbf{a}_{\mathbf{1}}$ and $\mathbf{a}_{\mathbf{1}}^{\text {proj }}$ are also indicated for each date.

\begin{tabular}{|c|c|c|c|c|c|c|c|c|c|c|c|}
\hline \multirow[b]{2}{*}{ Date } & \multicolumn{3}{|c|}{$\operatorname{RMSD}\left({ }^{\circ} \mathrm{C}\right)$} & \multicolumn{3}{|c|}{$\mathrm{R}(-)$} & \multicolumn{3}{|c|}{ Slope (-) } & \multirow{2}{*}{$\begin{array}{c}\mathbf{a}_{\mathbf{1}} \\
\left({ }^{\circ} \mathrm{C}\right)\end{array}$} & \multirow{2}{*}{$\begin{array}{l}\mathbf{a}_{1}^{\text {proj }} \\
\left({ }^{\circ} \mathrm{C}\right)\end{array}$} \\
\hline & D0 & D1 & D2 & D0 & D1 & D2 & D0 & D1 & D2 & & \\
\hline Dec 30 & 2.95 & 2.01 & 1.87 & 0.36 & 0.77 & 0.83 & 0.13 & 0.63 & 0.84 & -9.5 & -7.2 \\
\hline Apr 27 & 5.30 & 4.15 & 4.29 & 0.48 & 0.75 & 0.81 & 0.24 & 0.72 & 0.98 & -26 & -24 \\
\hline May 6 & 4.13 & 3.87 & 3.64 & 0.46 & 0.57 & 0.74 & 0.21 & 0.40 & 0.84 & -17 & -20 \\
\hline May 13 & 3.95 & 3.55 & 3.21 & 0.47 & 0.61 & 0.70 & 0.23 & 0.34 & 0.43 & -8.2 & -11 \\
\hline All & 4.08 & 3.40 & 3.25 & 0.44 & 0.68 & 0.77 & 0.20 & 0.52 & 0.77 & -15 & -16 \\
\hline
\end{tabular}


Table 3: The MODIS temperature re-sampled at $1 \mathrm{~km}$ resolution is disaggregated at $100 \mathrm{~m}$ resolution by D0, D1, and D2, and disaggregated temperature is compared to $100 \mathrm{~m}$ resolution ASTER temperature in terms of root mean square difference (RMSD), correlation coefficient (R), slope and mean difference (MD). The regression coefficients $\mathbf{a}_{\mathbf{1}}$ and $\mathbf{a}_{\mathbf{1}}^{\text {proj }}$ are also indicated for each date.

\begin{tabular}{|c|c|c|c|c|c|c|c|c|c|c|c|c|c|c|}
\hline \multirow[b]{2}{*}{ Date } & \multicolumn{3}{|c|}{$\operatorname{RMSD}\left({ }^{\circ} \mathrm{C}\right)$} & \multicolumn{3}{|c|}{$\mathrm{R}(-)$} & \multicolumn{3}{|c|}{ Slope (-) } & \multicolumn{3}{|c|}{$\mathrm{MD}\left({ }^{\circ} \mathrm{C}\right)$} & \multirow{2}{*}{$\begin{array}{c}\mathbf{a}_{1} \\
\left({ }^{\circ} \mathrm{C}\right)\end{array}$} & \multirow{2}{*}{$\begin{array}{l}\mathbf{a}_{1}^{\text {proj }} \\
\left({ }^{\circ} \mathrm{C}\right)\end{array}$} \\
\hline & D0 & D1 & D2 & D0 & D1 & D2 & D0 & D1 & D2 & D0 & D1 & D2 & & \\
\hline Dec 30 & 3.41 & 3.08 & 3.01 & 0.38 & 0.64 & 0.68 & 0.13 & 0.26 & 0.29 & -1.74 & -1.74 & -1.74 & -3.3 & -0.9 \\
\hline Apr 27 & 5.26 & 4.31 & 3.99 & 0.51 & 0.72 & 0.77 & 0.23 & 0.42 & 0.48 & -0.76 & -0.76 & -0.76 & -13 & -13 \\
\hline May 6 & 4.87 & 4.70 & 4.37 & 0.48 & 0.57 & 0.69 & 0.20 & 0.25 & 0.35 & -2.65 & -2.65 & -2.65 & -5.5 & -8.8 \\
\hline May 13 & 4.15 & 4.00 & 3.85 & 0.48 & 0.56 & 0.61 & 0.19 & 0.23 & 0.27 & -1.28 & -1.28 & -1.28 & -3.5 & -1.6 \\
\hline All & 4.42 & 4.02 & 3.81 & 0.46 & 0.62 & 0.69 & 0.19 & 0.29 & 0.35 & -1.61 & -1.61 & -1.61 & -6.3 & -6.1 \\
\hline
\end{tabular}


Table 4: The MODIS temperature re-sampled at $2 \mathrm{~km}$ resolution is disaggregated at $100 \mathrm{~m}$ resolution by D0, D1, and D2, and disaggregated temperature is compared to $100 \mathrm{~m}$ resolution ASTER temperature in terms of root mean square difference (RMSD), correlation coefficient (R), slope and mean difference (MD). The regression coefficients $\mathbf{a}_{\mathbf{1}}$ and $\mathbf{a}_{\mathbf{1}}^{\text {proj }}$ are also indicated for each date.

\begin{tabular}{|c|c|c|c|c|c|c|c|c|c|c|c|c|c|c|}
\hline \multirow[b]{2}{*}{ Date } & \multicolumn{3}{|c|}{$\operatorname{RMSD}\left({ }^{\circ} \mathrm{C}\right)$} & \multicolumn{3}{|c|}{$\mathrm{R}(-)$} & \multicolumn{3}{|c|}{ Slope (-) } & \multicolumn{3}{|c|}{$\mathrm{MD}\left({ }^{\circ} \mathrm{C}\right)$} & \multirow{2}{*}{$\begin{array}{c}\mathbf{a}_{1} \\
\left({ }^{\circ} \mathrm{C}\right)\end{array}$} & \multirow{2}{*}{$\begin{array}{l}\mathbf{a}_{1}^{\text {proj }} \\
\left({ }^{\circ} \mathrm{C}\right)\end{array}$} \\
\hline & D0 & D1 & D2 & D0 & D1 & D2 & D0 & D1 & D2 & D0 & D1 & D2 & & \\
\hline Dec 30 & 3.47 & 2.84 & 2.75 & 0.32 & 0.75 & 0.76 & 0.09 & 0.37 & 0.44 & -1.74 & -1.74 & -1.74 & -5.4 & -1.5 \\
\hline Apr 27 & 5.48 & 4.16 & 3.70 & 0.44 & 0.73 & 0.80 & 0.17 & 0.51 & 0.62 & -0.76 & -0.76 & -0.76 & -18 & -18 \\
\hline May 6 & 5.00 & 4.71 & 4.22 & 0.42 & 0.55 & 0.71 & 0.15 & 0.26 & 0.47 & -2.65 & -2.65 & -2.65 & -9.5 & -15 \\
\hline May 13 & 4.27 & 4.05 & 3.91 & 0.43 & 0.55 & 0.61 & 0.14 & 0.20 & 0.24 & -1.28 & -1.28 & -1.28 & -4.2 & -1.6 \\
\hline All & 4.55 & 3.94 & 3.64 & 0.40 & 0.65 & 0.72 & 0.14 & 0.33 & 0.44 & -1.61 & -1.61 & -1.61 & -9.3 & -9.0 \\
\hline
\end{tabular}


Table 5: The ASTER temperature aggregated at $1 \mathrm{~km}$ resolution is disaggregated at $100 \mathrm{~m}$ resolution by $\mathrm{D} 2 \mathrm{using}$ data set A, $\mathrm{B}$ and $\mathrm{C}$, and disaggregated temperature is compared to $100 \mathrm{~m}$ resolution ASTER temperature in terms of root mean square difference (RMSD), correlation coefficient (R) and slope. The regression coefficient $\mathbf{a}_{\mathbf{1}}^{\text {proj }}$ is also indicated.

\begin{tabular}{|c|c|c|c|c|c|c|c|c|c|c|c|c|}
\hline \multirow[b]{2}{*}{ Date } & \multicolumn{3}{|c|}{$\mathrm{RMSD}\left({ }^{\circ} \mathrm{C}\right)$} & \multicolumn{3}{|c|}{$\mathrm{R}(-)$} & \multicolumn{3}{|c|}{ Slope (-) } & \multicolumn{3}{|c|}{$\mathbf{a}_{1}^{\text {proj }}\left({ }^{\circ} \mathrm{C}\right)$} \\
\hline & $\mathrm{A}$ & B & $\mathrm{C}$ & $\mathrm{A}$ & B & $\mathrm{C}$ & $\mathrm{A}$ & B & $\mathrm{C}$ & $\mathrm{A}$ & $\mathrm{B}$ & $\mathrm{C}$ \\
\hline Dec 30 & 1.71 & 1.66 & 1.71 & 0.85 & 0.85 & 0.84 & 0.81 & 0.79 & 0.77 & -6.6 & -6.5 & -8.6 \\
\hline Apr 27 & 3.52 & 3.45 & 3.32 & 0.84 & 0.84 & 0.85 & 0.90 & 0.83 & 0.88 & -20 & -19 & -22 \\
\hline May 6 & 3.07 & 3.10 & 3.00 & 0.78 & 0.77 & 0.78 & 0.78 & 0.76 & 0.71 & -17 & -17 & -20 \\
\hline May 13 & 2.84 & 2.85 & 2.70 & 0.77 & 0.77 & 0.80 & 0.58 & 0.57 & 0.63 & -14 & -14 & -15 \\
\hline All & 2.78 & 2.76 & 2.68 & 0.81 & 0.81 & 0.82 & 0.77 & 0.74 & 0.75 & -14 & -14 & -16 \\
\hline
\end{tabular}


Table 6: The ASTER temperature aggregated at $1 \mathrm{~km}$ resolution is disaggregated at $100 \mathrm{~m}$ resolution by D2 (D1) using the $f_{\text {pav }}$ formulation from Gutman and Ignatov (1998) (GI98), Baret et al. (1995) (B95) and Carlson and Riplev (1997) (CR97).

Disaggregated temperature is compared to $100 \mathrm{~m}$ resolution ASTER temperature in terms of root mean square difference (RMSD), correlation coefficient (R) and slope.

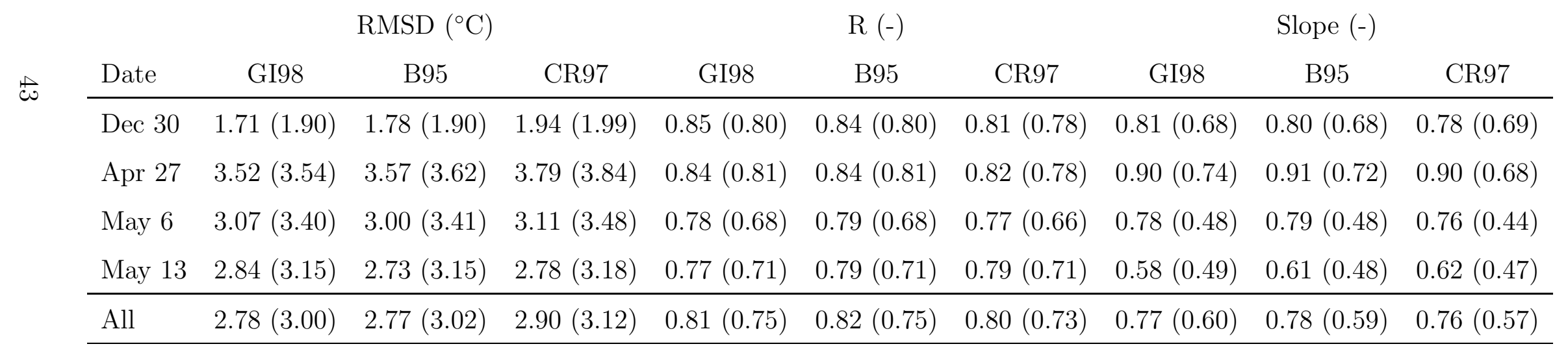



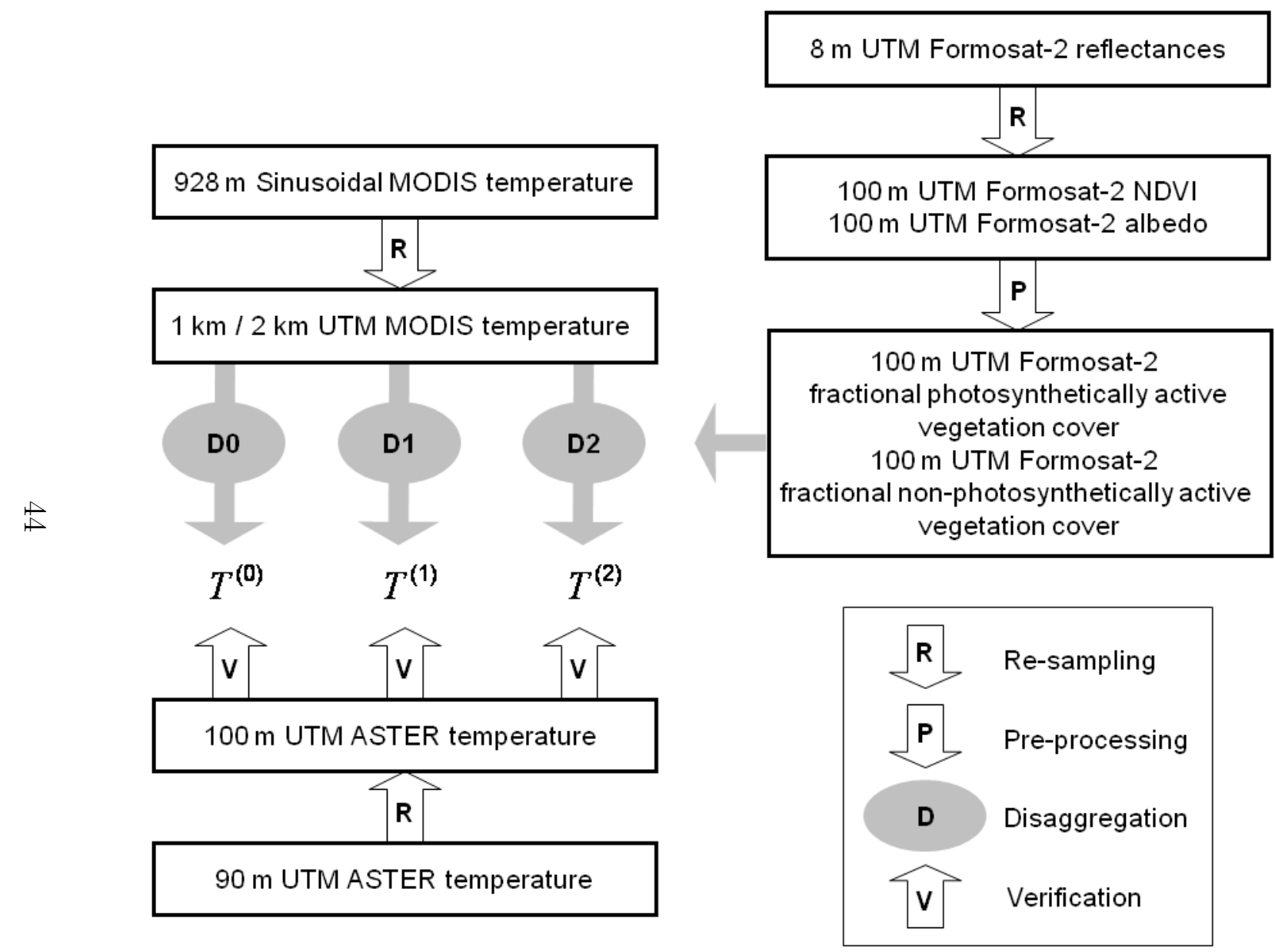

Figure 1: Schematic diagram presenting an overview of the re-sampling of Formosat-2, ASTER and MODIS data, the disaggregation algorithms D0, D1 and D2 and the verification strategy at $100 \mathrm{~m}$ resolution. 


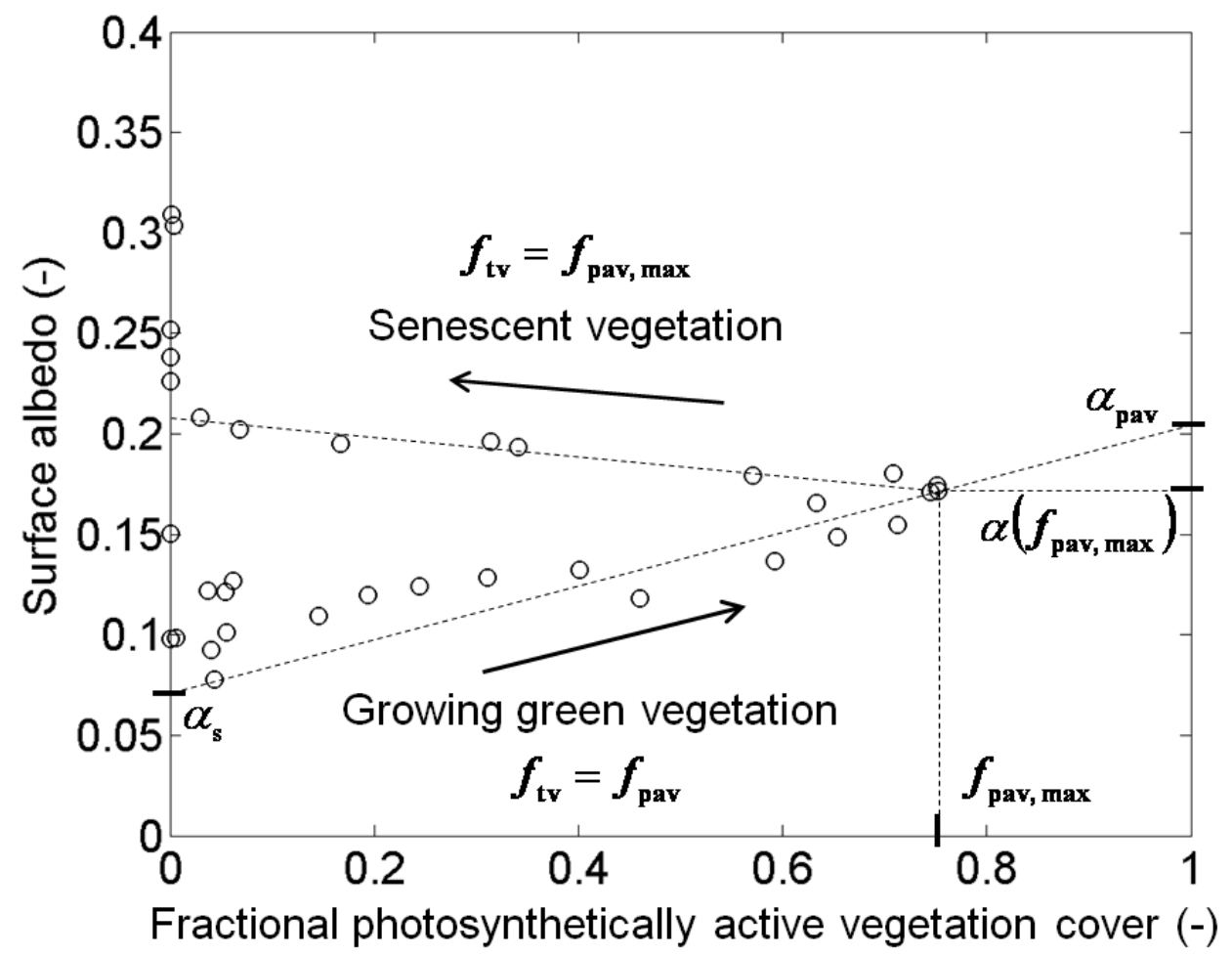

Figure 2: The variations of surface albedo $(\alpha)$ as function of fractional photosynthetically active vegetation cover $\left(f_{\text {pav }}\right)$ are used to estimate the fraction of total (photosynthetically plus non-photosynthetically active) vegetation $f_{\mathrm{tv}}$. Fractional vegetation cover $\left(f_{\mathrm{tv}}\right)$ is set to $f_{\text {pav }}$ during the growing period and to $f_{\text {pav, max }}$ during the senescence period. 


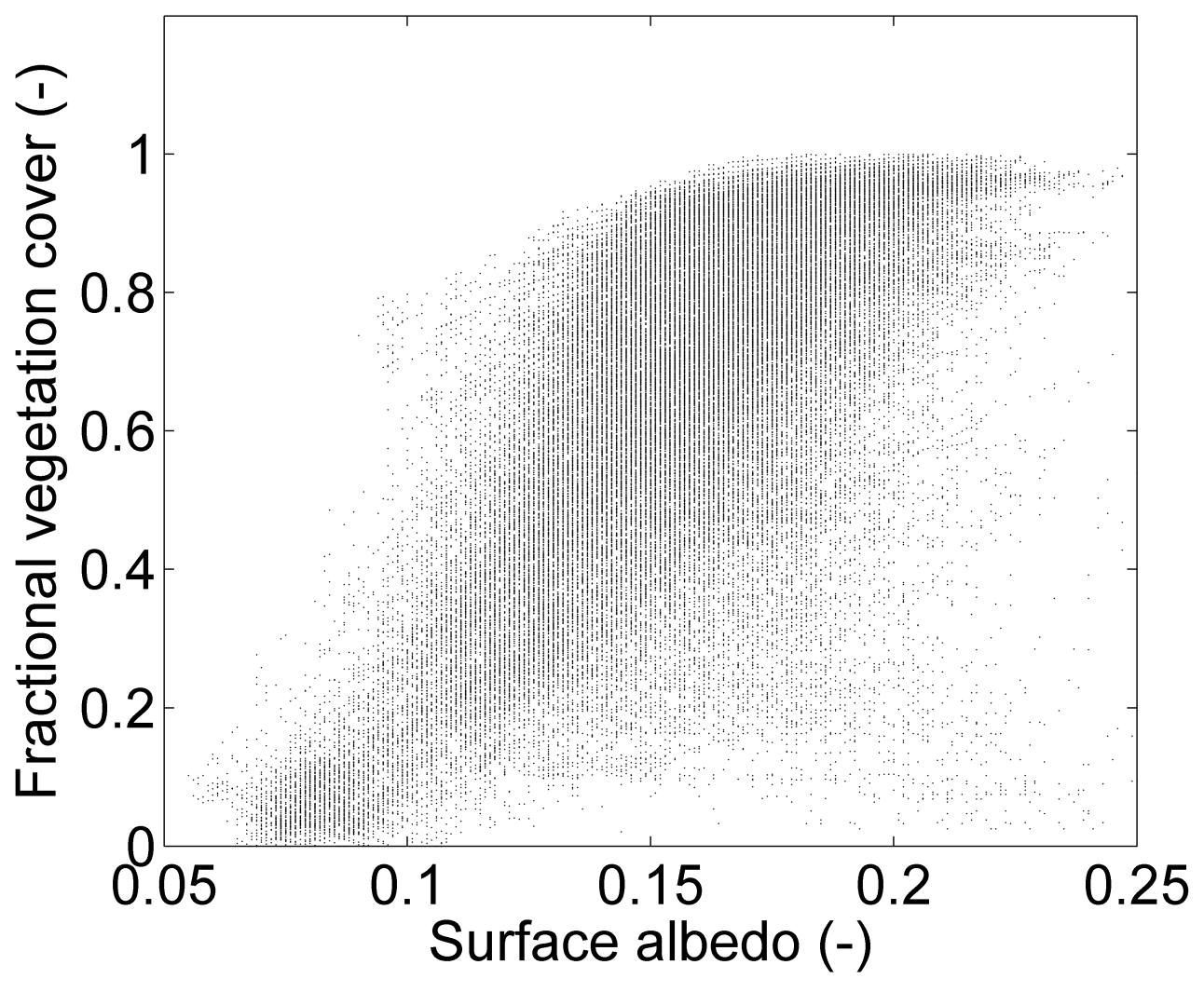

Figure 3: Fractional vegetation cover $\left(f_{\mathrm{tv}}\right)$ is plotted against surface albedo $(\alpha)$ for data on all dates. 

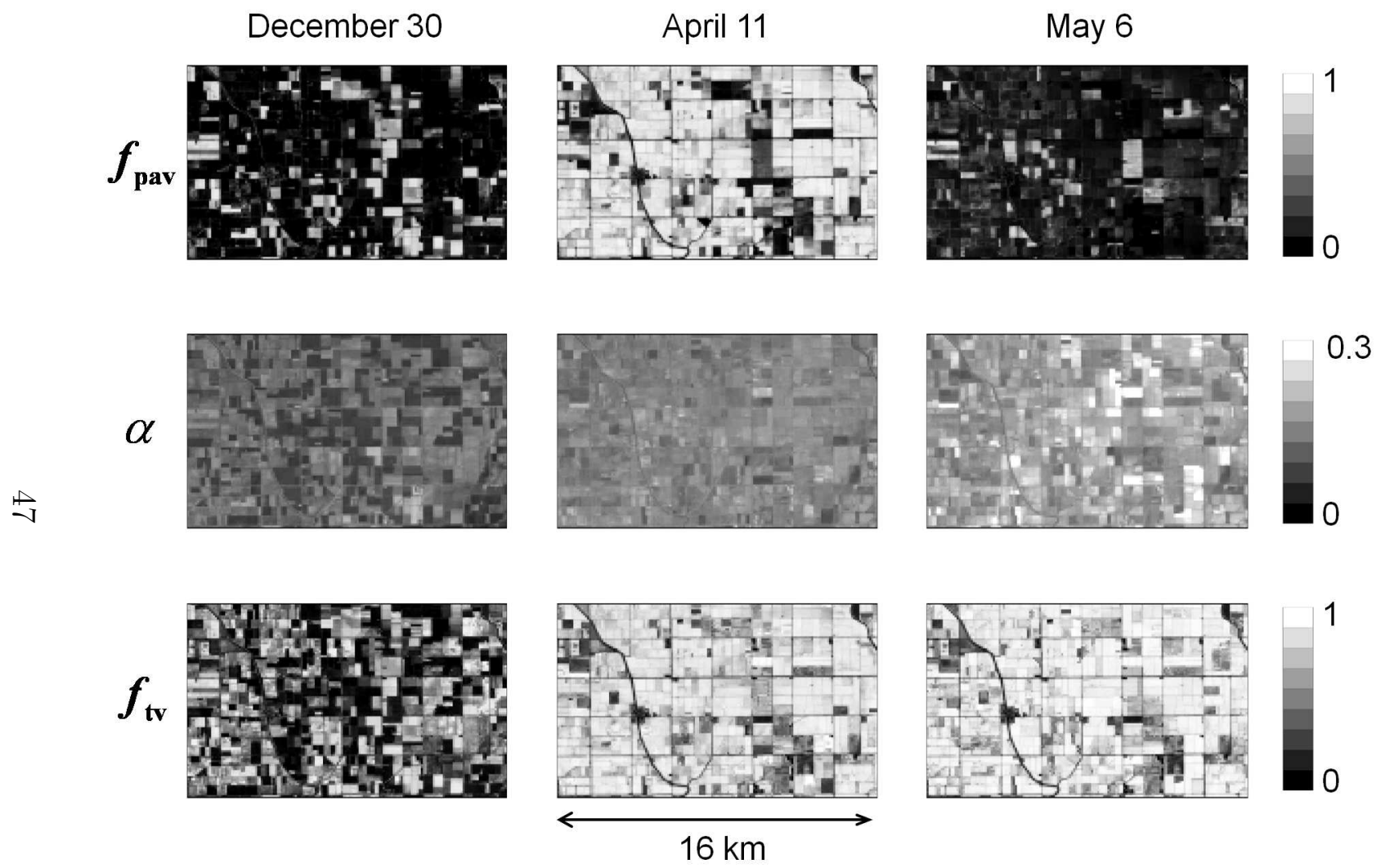

Figure 4: Images on December 30, April 11 and May 6 of fractional photosynthetically active vegetation cover $\left(f_{\text {pav }}\right)$, surface albedo $(\alpha)$ and fractional vegetation cover $\left(f_{\mathrm{tv}}\right)$ over the $16 \mathrm{~km}$ by $10 \mathrm{~km}$ study area. 

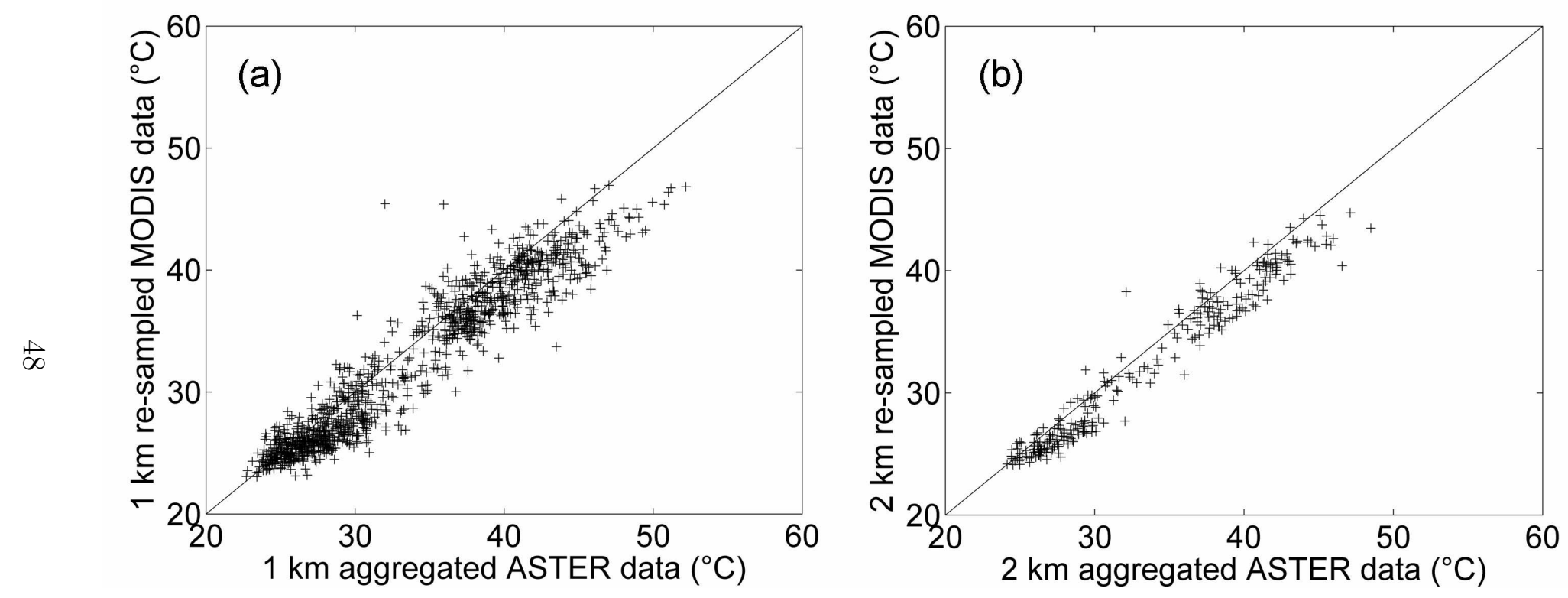

Figure 5: Re-sampled MODIS temperature is plotted against aggregated ASTER temperature for data at $1 \mathrm{~km}$ (left) and 2 $\mathrm{km}$ (right) resolution. 

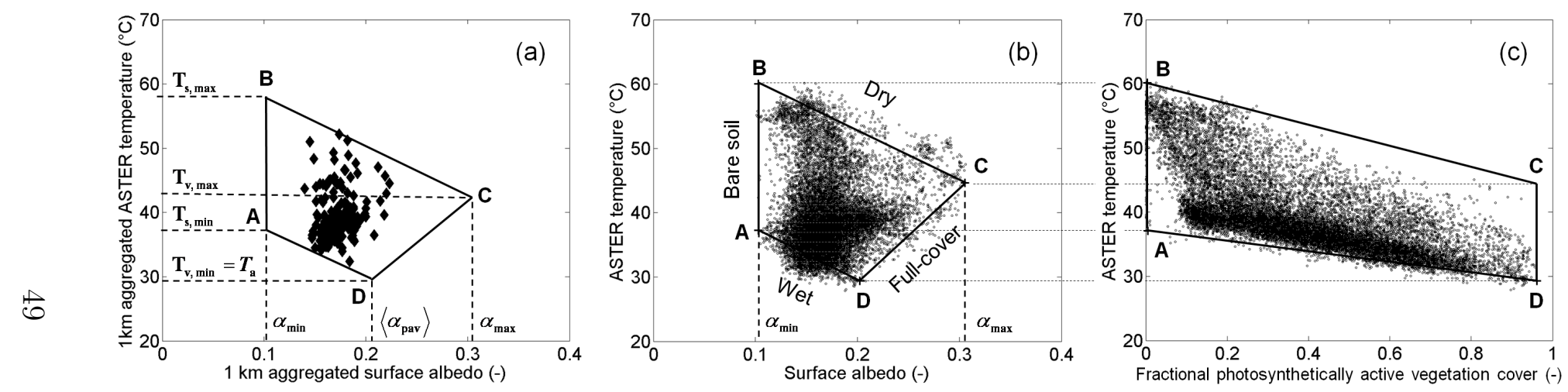

Figure 6: Scatterplot of $1 \mathrm{~km}$ resolution aggregated ASTER temperature versus $1 \mathrm{~km}$ resolution aggregated surface albedo (a), ASTER temperature versus surface albedo (b) and ASTER temperature versus fractional photosynthetically active vegetation cover (c). Extreme temperatures are estimated by intepreting the bare soil, dry surface, full-cover vegetation and wet surface edges of the polygon in (a). 

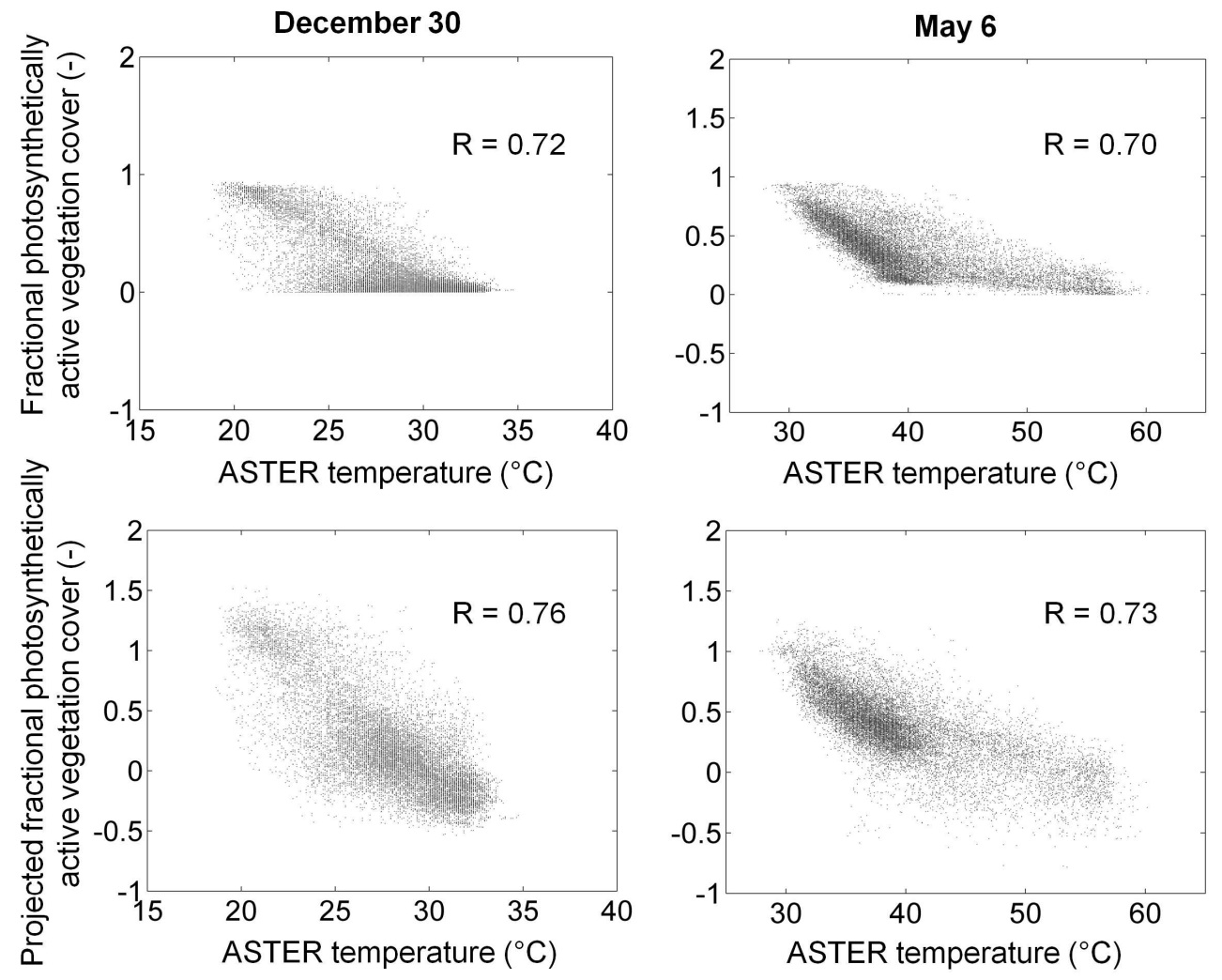

Figure 7: Scatterplot of fractional photosynthetically active vegetation cover $\left(f_{\text {pav }}\right)$ and projected fractional photosynthetically active vegetation cover $\left(f_{\mathrm{pav}}^{\mathrm{proj}}\right)$ versus ASTER temperature. 

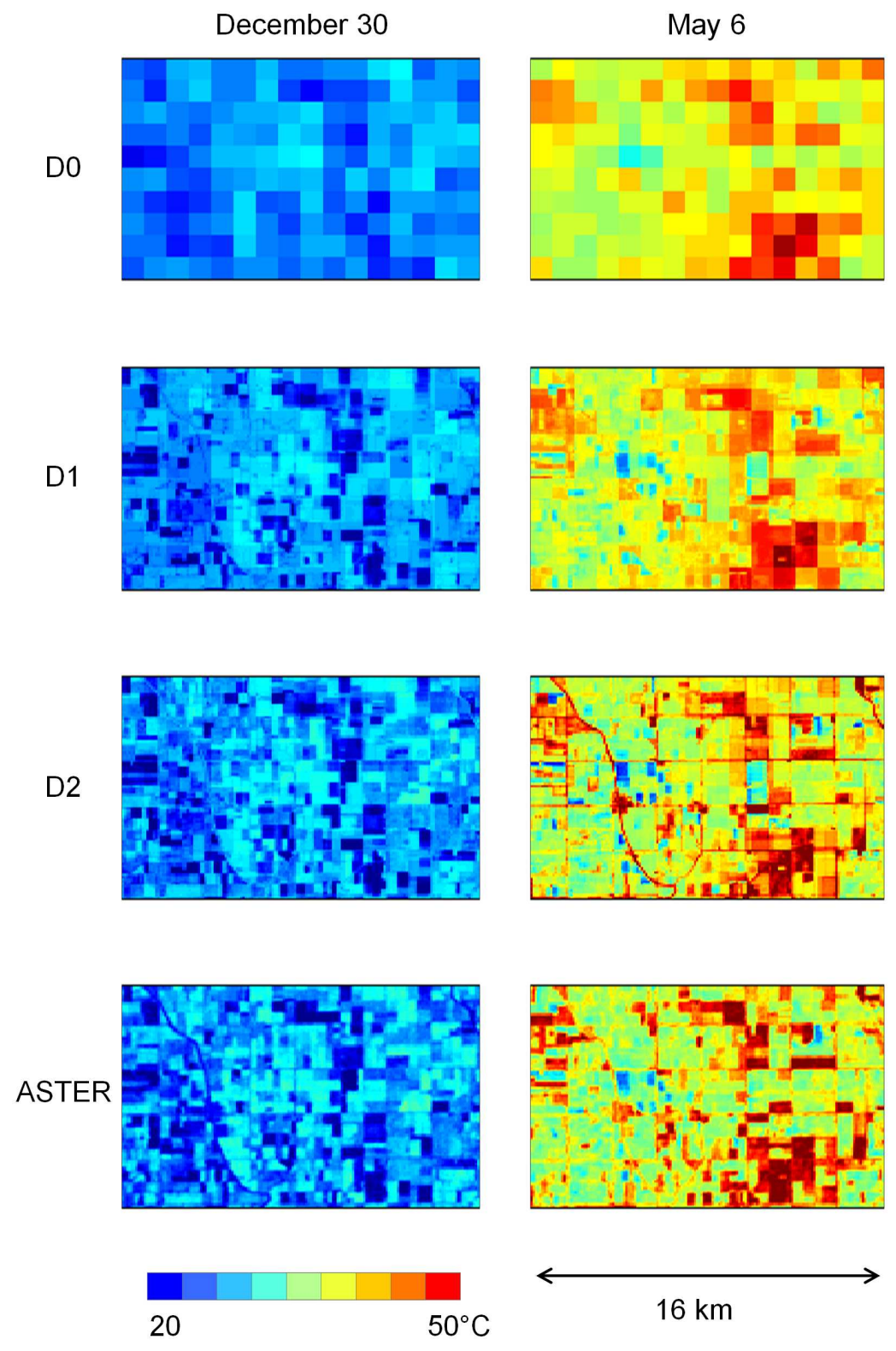

$16 \mathrm{~km}$

Figure 8: ASTER temperature compared to the temperature disaggregated by D0, D1 and D2 on December 30 (left) and May 6 (right). 


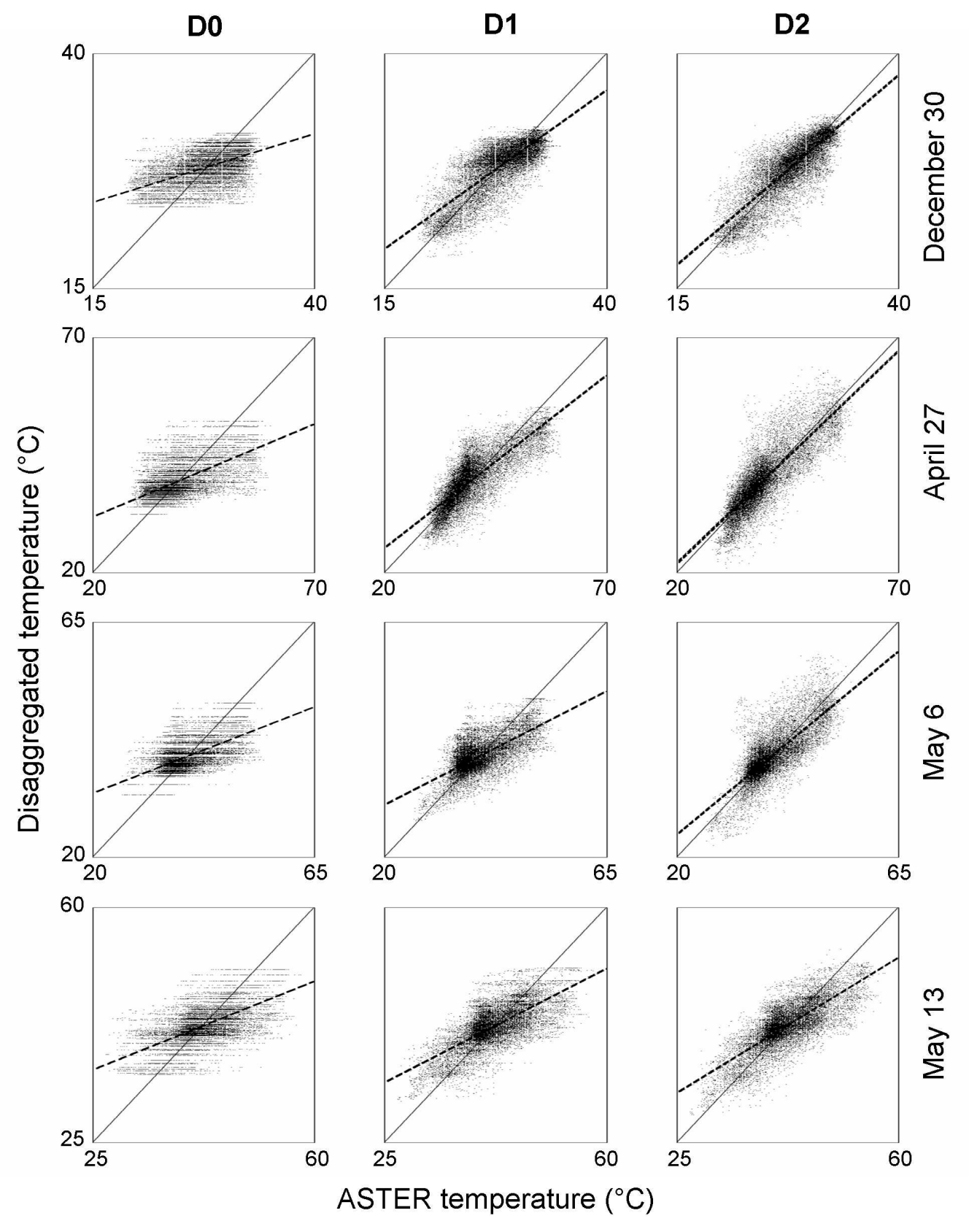

Figure 9: Scatterplot of the temperature disaggregated by D0, D1 and D2 versus ASTER temperature on December 30, April 27, May 6 and May 13. 